\title{
Immediate-Early Genes Modulation by Antipsychotics: Translational Implications for a Putative Gateway to Drug-Induced Long-Term Brain Changes
}

\author{
Andrea de Bartolomeis *, Elisabetta F. Buonaguro, Gianmarco Latte, Rodolfo Rossi, \\ Federica Marmo, Felice lasevoli and Carmine Tomasetti
}

Laboratory of Molecular and Translational Psychiatry and Unit of Treatment Resistant Psychosis, Section of Psychiatry, Department of Neuroscience, Reproductive Sciences and Odontostomatology, University School of Medicine "Federico II", Naples, Italy

OPEN ACCESS

Edited by: Amelia Gallitano, University of Arizona, United States

Reviewed by: Clive R. Bramham University of Bergen, Norway Gregg Stanwood, Florida State University, United States

*Correspondence: Andrea de Bartolomeis adebarto@unina.it

Received: 30 May 2017 Accepted: 22 November 2017 Published: 11 December 2017

Citation:

de Bartolomeis A, Buonaguro EF Latte $G$, Rossi R, Marmo F, lasevoli $F$ and Tomasetti C (2017) Immediate-Early Genes Modulation by

Antipsychotics: Translational Implications for a Putative Gateway to

Drug-Induced Long-Term Brain

Changes.

Front. Behav. Neurosci. 11:240. doi: 10.3389/fnbeh.2017.00240
An increasing amount of research aims at recognizing the molecular mechanisms involved in long-lasting brain architectural changes induced by antipsychotic treatments. Although both structural and functional modifications have been identified following acute antipsychotic administration in humans, currently there is scarce knowledge on the enduring consequences of these acute changes. New insights in immediate-early genes (IEGs) modulation following acute or chronic antipsychotic administration may help to fill the gap between primary molecular response and putative long-term changes. Moreover, a critical appraisal of the spatial and temporal patterns of IEGs expression may shed light on the functional "signature" of antipsychotics, such as the propensity to induce motor side effects, the potential neurobiological mechanisms underlying the differences between antipsychotics beyond D2 dopamine receptor affinity, as well as the relevant effects of brain region-specificity in their mechanisms of action. The interest for brain IEGs modulation after antipsychotic treatments has been revitalized by breakthrough findings such as the role of early genes in schizophrenia pathophysiology, the involvement of IEGs in epigenetic mechanisms relevant for cognition, and in neuronal mapping by means of IEGs expression profiling. Here we critically review the evidence on the differential modulation of IEGs by antipsychotics, highlighting the association between IEGs expression and neuroplasticity changes in brain regions impacted by antipsychotics, trying to elucidate the molecular mechanisms underpinning the effects of this class of drugs on psychotic, cognitive and behavioral symptoms.

Keywords: Arc, BDNF, Homer1a, clozapine, haloperidol, schizophrenia, bipolar disorders, cognition

\section{INTRODUCTION}

There is growing interest in unraveling the cellular mechanisms putatively involved in long-term changes in brain architecture and function following antipsychotic administration (Ahmed et al., 2008; Ho et al., 2011; Cannon et al., 2015; Vita et al., 2015; Yue et al., 2016; Emsley et al., 2017). In vivo human studies have pointed out that volumetric and functional changes may be detected after 
acute antipsychotic treatments (Emsley et al., 2015, 2017). However, the long-term consequences of these acute changes remain still elusive.

Immediate-early genes (IEGs) may represent a significant candidate to explore how acute antipsychotics administration may set the molecular scenario for long-term changes.

New insights in IEGs expression following acute or chronic antipsychotic administration in preclinical models may help to fill the gap between primary molecular responses to antipsychotic administration and putative long-term synaptic changes (Figure 1). Recent observations are opening new avenues in our understanding of how antipsychotics work and strongly challenge the old idea that significant changes in synaptic plasticity may be caused by prolonged treatments. Indeed, multiple lines of evidence demonstrated that in vivo antipsychotic treatment may significantly impact the architecture of the synapse, as well as the re-arrangement of gene expression of scaffolding and adaptor proteins after acute exposure to the drugs. In line with this view, haloperidol acute administration has been shown to reduce dendritic spines size, possibly through a beta-adducin-mediated mechanism (Engmann et al., 2016). Moreover, the acute administration of typical and atypical antipsychotics has been demonstrated to re-arrange the topography of Homerla gene expression in cortical and subcortical brain regions (Buonaguro et al., 2017b).

Acute antipsychotics administration has been demonstrated to impact signal-transduction pathways in specific brain regions with significant implications for long-term treatment (De Bartolomeis et al., 2013b, 2015a). For instance, acute i.v. infusion at therapeutic doses of haloperidol may trigger changes in the volume of the striatum (Tost et al., 2010), this effect being consistent with the rapid and transient IEGs induction by acute dopamine D2 receptors (D2Rs) blockade.

IEGs activation after antipsychotics acute administration could be pivotal to dissect primary molecular and cellular events that may prime the long-term effects of antipsychotic treatment. Similarly, multiple studies have pointed out the significant functional changes in cortical and subcortical networks after acute administration of antipsychotics (Emsley et al., 2015, 2017).

At the same time, new exciting discoveries in early gene functions have reinvigorated the research on the role of IEGs in the brain, thanks also to novel techniques, such as the following: serial two-photon tomography (STP) for automated whole-brain histology using fluorescent reporters (Ragan et al., 2012); light sheet fluorescence microscopy (LSFM) coupled with tissue clearing for imaging IEG expression in the intact brain (Renier et al., 2016); optogenetics for selectively activate target neurons (Bepari et al., 2012).

Despite the relevance of the issue, the role of IEGs in antipsychotics action has not been reviewed recently and a comprehensive analysis is still lacking.

Herein, starting from the major IEGs proven to be induced by antipsychotics and from their involvement in brain functions believed to be translationally relevant for schizophrenia as well as for antipsychotic mechanism of action, we will review the following issues:
1) IEGs regulation with focus on dopamine-related mechanisms relevant for or related to antipsychotics action;

2) IEGs expression in psychosis and differential modulation by antipsychotics.

Moreover, we will consider:

1) How IEGs induction may impact directly or indirectly synaptic architecture;

2) How IEGs are differentially affected by acute and chronic antipsychotic treatment;

3) How antipsychotics with different receptor profile or the same antipsychotic at different doses may affect the expression of different IEGs with regard of brain topography.

\section{BACKGROUND: ANTIPSYCHOTICS, IEGs, AND BRAIN CHANGES}

\section{IEGs Relevance for Synaptic Plasticity}

IEGs are a heterogeneous class of genes that are rapidly and transiently activated by a large number of stimuli, including environmental (i.e., light/dark phase changes, exposure to behavioral stressors such as intruder animals, learning session during acquisition tasks), pharmacological, and physical stimuli (Perez-Cadahia et al., 2011; Sauvage et al., 2013). IEGs represent a primary response to cellular perturbation, which is a standing process that is activated at the transcriptional level and occurs in the absence of de novo protein synthesis. IEGs are dynamically regulated by different forms of synaptic activity underlying information processing and storage, therefore they are excellent candidates involved in both Hebbian and homeostatic plasticity (Hu et al., 2010; Hayashi et al., 2012; Shin et al., 2012). Several studies demonstrated, indeed, that long-term forms of synaptic plasticity-such as long-term potentiation (LTP) require new production of intracellular macromolecules, whereas short-term synaptic plasticity processes do not (Kandel, 2001; Hayashi et al., 2012). IEGs expression occurring promptly after stimuli is considered a fundamental step for the establishment of synaptic plasticity, since synaptic plasticity changes may be prevented when mRNA synthesis is blocked early after the induction of a stimulus (Lanahan and Worley, 1998). Thus, IEGs may be considered as "gateway" genes controlling synaptic plasticity and may underlie processes like learning and memory formation.

IEGs encode a large number of proteins with different functions, such as transcription factors (e.g., c-Fos, Egr1, NGFIB), postsynaptic proteins (e.g., Norbin, Homer 1a, Arc) and signaling molecules (e.g., RSG2, CaMKII).

The induction of an IEG is one of the earliest intracellular mechanism mediating the cellular response to external stimuli (Lanahan and Worley, 1998). According to these view, IEGs induction may be considered a recent activity marker, and its assessment may be used to determine when specific neural populations are activated, making possible to assess the extent of antipsychotics spatial and temporal impact on neural plasticity in different brain areas. 

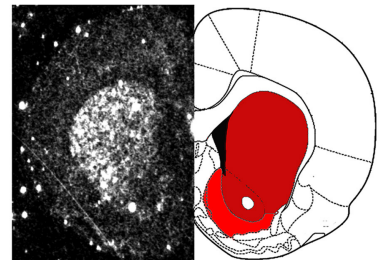

HAL

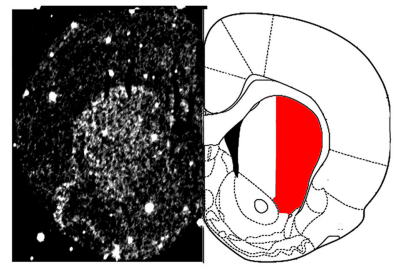

RISP

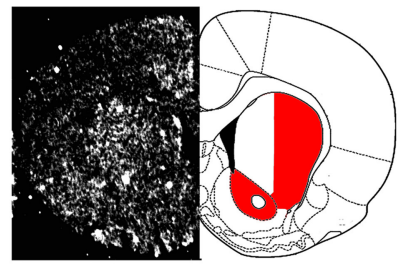

OLA

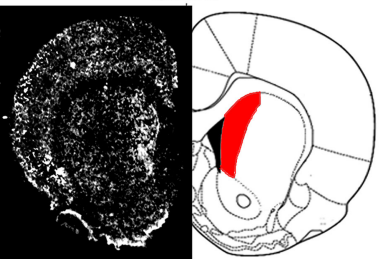

AMS

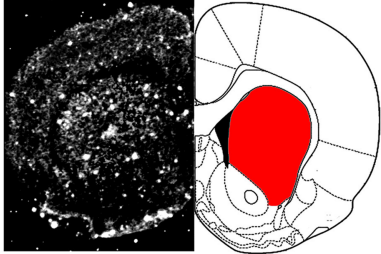

ARI12
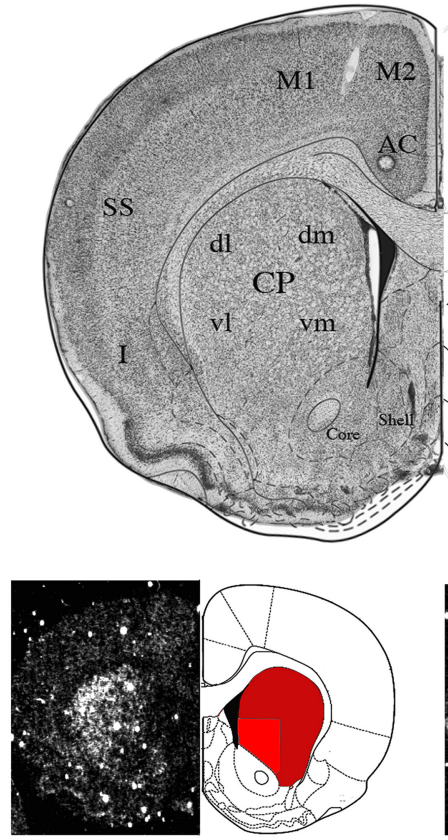

ZIP4

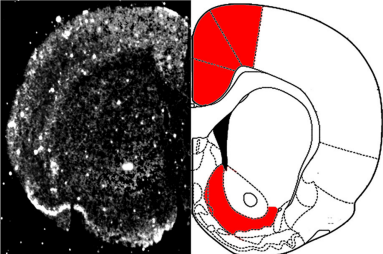

ARI30
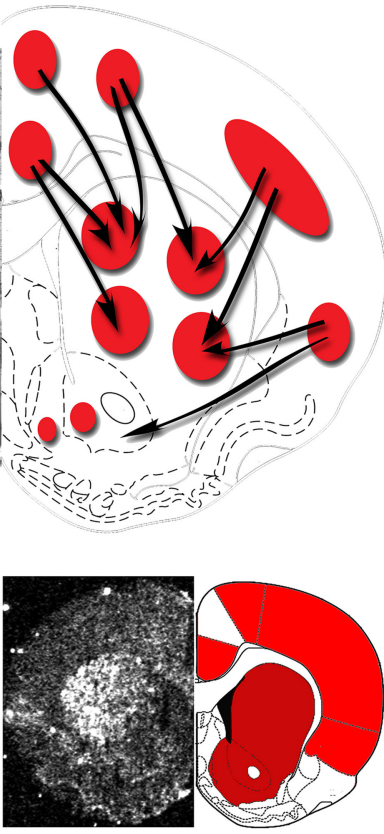

ZIP10

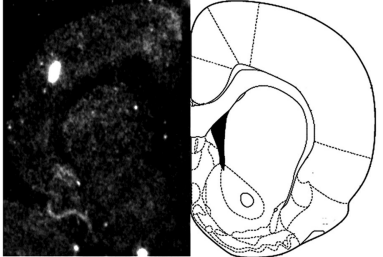

QUE15

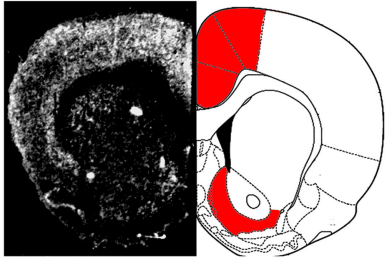

QUE30

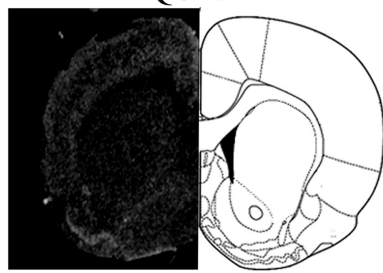

SERT

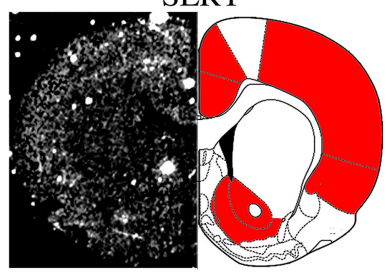

CLO

FIGURE 1 | Representative molecular imaging of Homer1a IEG expression by acute antipsychotics administration. Molecular imaging of IEGs expression may represent a tool to investigate topographic distribution of antipsychotic-mediated acute and long-term molecular effects within brain Regions of Interest (ROIs). Here we show a representative depiction of Homer1a IEG expression by different antipsychotics acutely administered in rodents. The autoradiographic film images of Homer1a mRNA detected by means of in situ hybridization histochemistry in coronal brain sections have been extracted from different studies carried on by our laboratory (Polese et al., 2002; Ambesi-Impiombato et al., 2007; Tomasetti et al., 2007, 2011; lasevoli et al., 2009, 2010a,b, 2011; De Bartolomeis et al., 2015a) and representatively placed side by side in order to outline gene expression topography after treatments with haloperidol (HAL), olanzapine (OLA), sertindole (SERT), amisulpiride (AMS), risperidone (RISP), clozapine (CLO), and different doses of ziprasidone (4 mg/kg, ZIP4; 10 mg/kg, ZIP10), aripriprazole (12 mg/kg, ARI12; 30 $\mathrm{mg} / \mathrm{kg}$, ARI30), quetiapine (15 mg/kg, QUE15; $30 \mathrm{mg} / \mathrm{kg}$, QUE30). Homer1a is a postsynaptic effector of plastic synaptic changes mainly mediated by dopamine and glutamate-dependent signaling pathways. Therefore, in this case, IEG molecular imaging may also provide putative information on antipsychotic-triggered changes in synaptic plasticity. ROls: AC, Anterior Cingulate Cortex; M2, Medial Agranular Cortex; M1, Motor Cortex; SS, Somatosensory Cortex; I, Insular Cortex; dmCP, Dorso Medial Caudate-Putamen; dICP, Dorso Lateral Caudate-Putamen; vICP, Ventro Lateral Caudate-Putamen; vmCP, Ventro Medial Caudate-Putamen; Core, Nucleus Accumbens; Core, Shell, Nucleus Accumbens, Shell. Red, significant gene induction as compared to the respective control $(p<0.05)$; Dark red, significant gene induction as compared to the respective control $(p<0.001)$.

\section{IEGs: A Putative Gateway for Antipsychotic-Induced Brain Changes}

Antipsychotic drugs are the mainstay of pharmacological treatment for schizophrenia, and their use has been expanded for the treatment of bipolar disorder and, in some cases, for pervasive disorders of the autistic spectrum (Geddes and Miklowitz, 2013). All antipsychotics share a variable degree of antagonism, or partial agonism, at D2 dopamine receptors (D2Rs) and both therapeutic and motor side effects of either typical or atypical antipsychotic drugs have been proven to directly depend on the occupancy of D2Rs (Seeman, 2002; Ginovart and Kapur, 2012). However, besides the dynamics of D2Rs binding by different antipsychotics, emerging evidence demonstrates that the study of the downstream signaling elicited by these compounds may help to better understand the mechanisms of action implicated in their clinical effects (De Bartolomeis et al., 2013a; Iasevoli et al., 2013). Additionally, dissecting the molecular basis of antipsychotic actions may shed light on new avenues of investigation to bypass the critical issues related to receptor pharmacodynamics, such as D2Rs down- or up-regulation and D2Rs supersensitivity, which have been considered among the potential reasons of antipsychotic treatment resistance (Seeman, 2002; Nnadi and Malhotra, 2007; Seeman and Seeman, 2014; Oda et al., 2015). 
In the last decades, several studies on the effects of typical and atypical antipsychotics on brain IEGs expression have been carried out, trying to unravel the bases of regional neuronal response to pharmacological stimuli (Dragunow, 1990; Miller, 1990; Young et al., 1998; Semba et al., 1999; Beaudry et al., 2000; Kovacs et al., 2001; Cochran et al., 2002), as well as to shed light on the molecular mechanisms implicated in antipsychotic actions (Deutch et al., 1991, 1995). Transcriptional fingerprint of IEGs, and their functionally related molecules, has progressively emerged as a potential methodology to explore temporal and functional brain regions recruitment by antipsychotics and psychotomimetic compounds (Gonzalez-Maeso et al., 2003; Tomasetti et al., 2007; Sakuma et al., 2015). Moreover, IEGs have been found to be modulated also by other psychotropic drugs, such as antidepressants (De Foubert et al., 2004; Alme et al., 2007; Molteni et al., 2008; Calabrese et al., 2011), mood stabilizers (De Bartolomeis et al., 2012), as well as by the combination of antipsychotics and antidepressants or mood stabilizers, which has been demonstrated to differentially induce IEGs patterns of expression as compared to the compounds when individually administered (Dell'aversano et al., 2009; Tomasetti et al., 2011).

\section{LITERATURE RESEARCH METHODOLOGY}

As a first step, we carried out multiple searches on Pubmed, Scopus, and ISI Web of Knowledge using as a reference the following keywords (we reported in parentheses the results obtained on Pubmed for the search conducted on May 2017): Immediate Early Genes AND brain (2335); Immediate Early Genes AND antipsychotics (84); Immediate early genes AND antipsychotics AND brain (74). Successively, we searched by the name of each single IEG or related gene of interest, together with the keywords "brain" AND/OR "antipsychotics." The name of the IEGs or related genes searched were: Arc/Arg, BDNF, cfos, fos, c-Jun, jun, Egr1, Delta-fos, Narp1, NPAS-4, Homer1, Homer2, Homer3, Nor1, Nurr, Nurr1, NGFI-B/Nur77, Nerve Growth Factor Inducible-B, NR4A.

A "parallel search" was conducted using as key words the combination the following ones: antipsychotics AND acute effects, antipsychotics AND brain volume, antipsychotics AND cortical thickness, antipsychotics AND acute AND PET, antipsychotics AND acute AND fMRI, antipsychotics AND brain changes.

For the above-mentioned first search (keywords: Immediate Early Genes AND brain), each abstract retrieved was considered for coherence of the subject with the content of the review by two independent co-authors. If the text of the abstract was coherent with the review, the full text was considered and the references double-checked for potential new articles of relevance. All the articles retrieved with the second search (Immediate-early genes AND antipsychotics) and the third search (Immediateearly genes AND antipsychotics AND brain), as well as the articles retrieved by the search for single early gene name, were considered for the full text. The results of the first search where then compared with the result of the other searches and with the one of the "parallel search."

\section{C-fos, $\triangle$ FosB, C-Jun: MAPPING THE NEURAL ACTIVITY IN RESPONSE TO ANTIPSYCHOTICS, OLD AND NEW FINDINGS}

Synaptic plasticity processes occurring in response to neural activity are mediated by complex programs of gene expression controlled by transcription factors (TFs; Beckervordersandforth et al., 2015; Ortega-Martinez, 2015; Ehrlich and Josselyn, 2016).

Antipsychotics have been demonstrated to differentially impact IEGs encoding neural TFs, thus inducing a significant reprogramming in the expression of genes involved in synaptic plasticity (Figure 2; Table 1).

\section{C-fos: The Prototypical IEG C-fos Regulation by Dopamine}

$C$-fos is a proto-oncogene encoding for a TF that is induced in response to multiple stimuli, included neural activity (Durchdewald et al., 2009). In resting conditions, the product of the $c$-fos gene, the Fos protein, is expressed in small amounts in the brain.

$C$-fos transcription may be activated in response to many different extracellular signals, including growth factors and neurotransmitters, such as dopamine. Several early studies demonstrated that transcriptional regulation after dopaminergic stimuli, such as amphetamine/cocaine administration, is a pivotal mechanism by which neurons may respond to environmental adaptations (De Bartolomeis et al., 2013b). The phosphorylation of the cAMP response element binding protein (CREB) is crucial to couple dopamine stimulation to the IEG transcription. Indeed, signals starting at dopamine receptors may promote CREB phosphorylation, which in turn regulates $c$-fos transcription. When translated, the Fos protein may dimerize with members of Jun family in order to start the formation of the Activator Protein-1 heterocomplex (AP-1), which in turn may trigger the expression of genes involved in cell proliferation and differentiation, as well as in activity-stimulated synaptic rearrangements (Herrera et al., 1990).

Based on its fast induction dynamics, c-fos expression has been widely used to characterize the different topographic patterns of neural activation following treatments with different antipsychotics (Nguyen et al., 1992; Merchant et al., 1994).

\section{C-fos in Schizophrenia and Its Modulation by Antipsychotics}

Recent human studies have pointed out that specific polymorphisms of $c$-fos gene may be either negatively or positively associated to schizophrenia, since decreased Fos protein blood levels may be found in schizophrenia patients (Boyajyan et al., 2015), thus reinforcing the possibility of an implication of this IEG in schizophrenia pathophysiology and, possibly, in its treatment.

Early studies observed that typical and atypical antipsychotics may induce different patterns of $c$-fos activation in cortical and subcortical brain regions. Indeed, typical antipsychotics, such as haloperidol, may induce $c$-fos expression in the dorso-lateral 


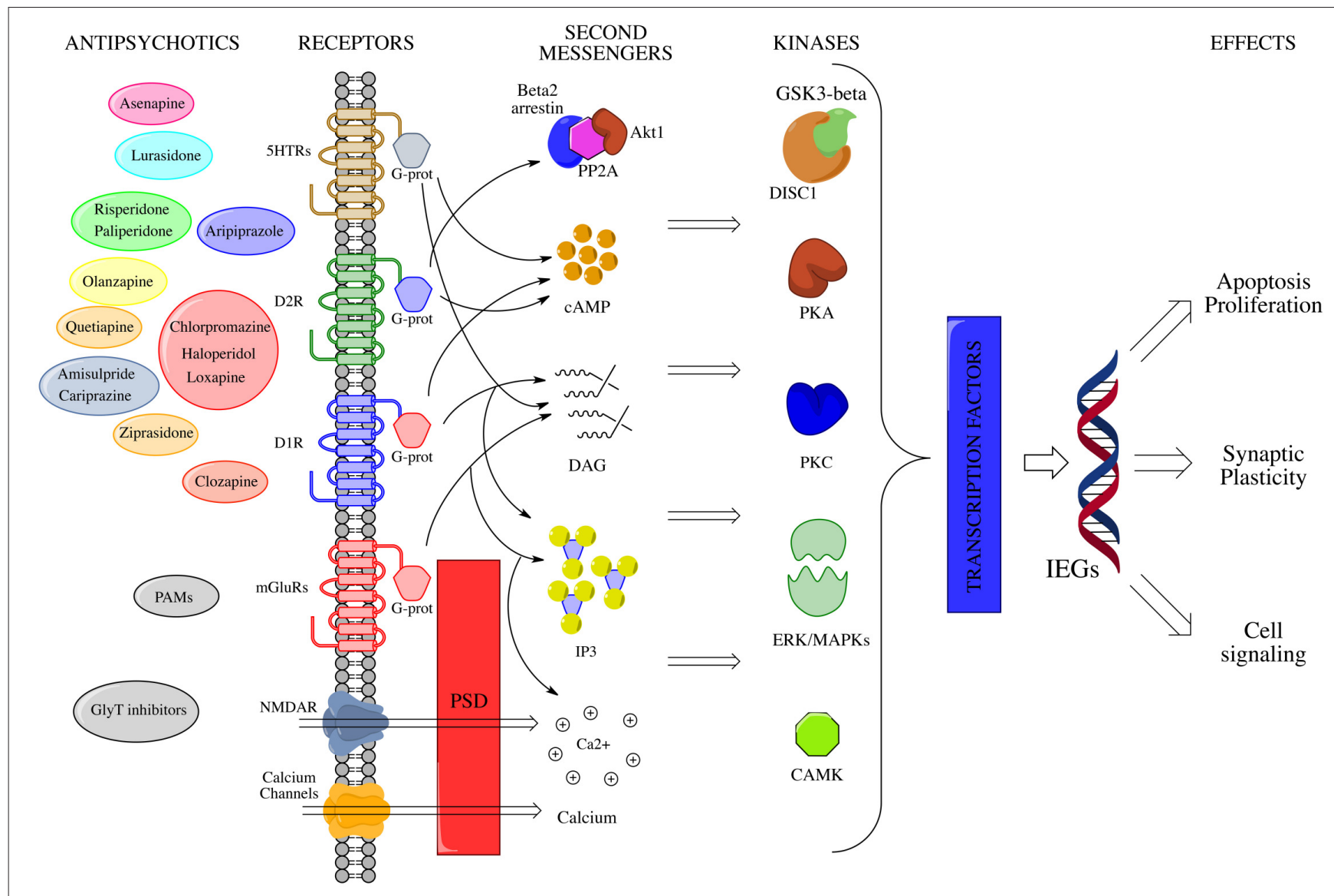

FIGURE 2 | IEGs modulation by antipsychotic drugs. Membrane receptors activate multiple signal transduction pathways, which interact at several sites through the mediation of a large number of second messengers. A crucial role in the post-membrane interaction is played by the PSD, which serves as a physical connection among ionotropic and metabotropic glutamate receptors, and links them to intracellular calcium stores. All these pathways converge in the end to appropriate nuclear targets (i.e., transcription factors, TFs) via specific effectors, largely kinases (e.g., CAMK, MAPKs, PKA etc.), in order to fine modulate long-term activity dependent neuronal rearrangements through changes in IEGs expression levels. On the left side of the picture, antipsychotic compounds are depicted near to the membrane receptors to which they show maximum affinity. NMDAR, N-methyl-D-aspartate glutamate receptor; mGluR1a/5, metabotropic glutamate receptor type 1a/5; D1, dopamine receptor D1; D2, dopamine receptor D2; DAG, diacylglycerol; IP3, inositol 1,4,5-trisphosphate; Akt1, RAC-alpha serine/threonine-protein kinase; PP2A,

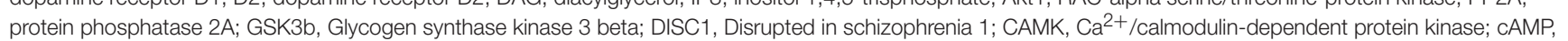
cyclic adenosine monophosphate; PKC, protein kinase C; PKA, protein kinase A; MAPKs, mitogen-activated protein kinases; ERK, extracellular signal-regulated kinase; CREB-P, cAMP response element-binding protein; IEGs, immediate early genes; PSD, post-synaptic density; PAMs, positive allosteric modulators of mGluRs; GlyT, glycine transporter.

regions of the striatum, as well as in the nucleus accumbens and in the lateral septum. Atypical antipsychotics, such as clozapine, were found to induce $c-f o s$ expression in prefrontal cortex and medial striatum (Robertson et al., 1994). Since the dorso-lateral striatum has been implicated in motor control (Balleine and O'doherty, 2010), it has been suggested that the liability of an antipsychotic drug to induce extrapyramidal side-effects (EPSEs) might be predicted by its propensity to induce $c$-fos expression in the motor circuits of the striatum (Robertson and Fibiger, 1996). On the other hand, the induction of $c-f o s$ expression in prefrontal cortex and limbic striatum by atypical antipsychotics (e.g., clozapine; Robertson et al., 1994) has been potentially correlated with the ability of these compounds to impact, at least in part, brain circuitry implicated in the pathophysiology of negative symptoms of schizophrenia, based on the hypothesis explaining negative symptoms with a potential hypo-frontality in schizophrenia patients (Weinberger and Berman, 1996). However, this observation should nowadays be discussed with caution, considering recent advances in molecular characterization of old and novel antipsychotics, as well as the latest results on the real effect size of atypical antipsychotics on negative symptoms (Kantrowitz, 2017).

Typical and atypical antipsychotics differentially enhance $c$ fos expression in the two histological compartments of the striatum, striosome, and matrix. Indeed, typical antipsychotics induce $c$-fos at a similar extent in the striosome and in the matrix, while most atypical antipsychotics preferentially induce $c$-fos in the striosome (Hiroi and Graybiel, 1996; Bubser and Deutch, 2002). It is noteworthy that no difference in the striosome/matrix ratio (SMR) has been found for typical antipsychotics between dorso-lateral caudate-putamen and dorso-medial caudate-putamen, while clozapine showed a 
TABLE 1 | Detection of IEGs expression evaluation in rodents after antipsychotics administration.

\begin{tabular}{|c|c|c|c|c|}
\hline Gene & Drug & $\begin{array}{l}\text { Effect on gene } \\
\text { expression }\end{array}$ & Brain region & References \\
\hline \multirow[t]{8}{*}{$c$-fos } & Acute Amisulpride & $\uparrow$ & Medial Striatum & De Bartolomeis et al., 2013b \\
\hline & Acute Clozapine & $\uparrow$ & NAc, Thalamus, Striatum & Robbins et al., 2008 \\
\hline & Acute Clozapine & $\uparrow$ & NAc Shell & Werme et al., 2000; Polese et al., 2002 \\
\hline & Acute Haloperidol & $\uparrow$ & $\begin{array}{l}\text { NAc Shell and Core, } \\
\text { Medial, and Lateral Caudate Putamen, } \\
\text { Lateral septum }\end{array}$ & $\begin{array}{l}\text { Robertson et al., 1994; Werme et al., } 2000 \\
\text { Robbins et al., } 2008 \\
\text { Polese et al., } 2002 \\
\text { De Bartolomeis et al., 2015a }\end{array}$ \\
\hline & Acute Haloperidol or acute Clozapine & $\uparrow$ & Anteroventral Thalamus & Cochran et al., 2002 \\
\hline & Acute but not chronic Risperidone & $\uparrow$ & Striatum & Robinet et al., 2001 \\
\hline & $\begin{array}{l}\text { Transient treatment with Haloperidol but } \\
\text { not continuous treatment }\end{array}$ & $\uparrow$ & Striatum & Samaha et al., 2008 \\
\hline & $\begin{array}{l}\text { Chronic Clozapine } \\
\text { (after } 6 \text { days of washout) }\end{array}$ & $\uparrow$ & PFC, FC, NAc Core & Kontkanen et al., 2002 \\
\hline \multirow{2}{*}{$c$-jun } & Acute Haloperidol & $\downarrow$ & NAc & Robbins et al., 2008 \\
\hline & Chronic Clozapine & $\uparrow$ & FC, NAc Shell & Kontkanen et al., 2002 \\
\hline \multirow[t]{6}{*}{ Nur family } & $\begin{array}{l}\text { Acute Typical antipsychotics on Nurr1, } \\
\text { Nur77 and Nor-1 }\end{array}$ & $\uparrow$ & Striatum & Maheux et al., 2005 \\
\hline & Acute Clozapine on Nor1 and Nurr77 & $\uparrow$ & NAc Shell & Werme et al., 2000 \\
\hline & Acute Haloperidol On Nor1 and Nurr77 & $\uparrow$ & $\begin{array}{l}\text { NAc Shell and Core, } \\
\text { medial, and lateral Caudate Putamen. }\end{array}$ & Werme et al., 2000 \\
\hline & $\begin{array}{l}\text { Acute Clozapine or Haloperidol on } \\
\text { Nurr77 }\end{array}$ & $\uparrow$ & PFC, cingulate cortex and NAc Shell & Beaudry et al., 2000 \\
\hline & Acute and chronic Haloperidol on Nurr77 & $\uparrow$ & Lateral striatum & \\
\hline & $\begin{array}{l}\text { Chronic Haloperidol or Clozapine on } \\
\text { Nurr77 }\end{array}$ & $\downarrow$ & Primary Somato-sensory cortex & Langlois et al., 2001 \\
\hline Egr1 & Chronic Olanzapine & $\downarrow$ & PFC, Locus Coeruleus & Verma et al., 2006, 2007 \\
\hline \multirow[t]{11}{*}{ Arc } & Acute Asenapine & $\downarrow$ & $\mathrm{PFC}$ & De Bartolomeis et al., 2015a \\
\hline & Acute high dose Asenapine & $\uparrow$ & Striatum, NAc Core & De Bartolomeis et al., 2015a \\
\hline & Acute Clozapine & $\downarrow$ & Thalamus, mPFC, Cingulate cortex & Robbins et al., 2008 \\
\hline & $\begin{array}{l}\text { Acute Haloperidol or Olanzapine or } \\
\text { High dose Amisulpiride }\end{array}$ & $\uparrow$ & Striatum & $\begin{array}{l}\text { Robbins et al., 2008; Fumagalli et al., 2009; } \\
\text { lasevoli et al., 2010b; De Bartolomeis et al., 2013b }\end{array}$ \\
\hline & Acute Haloperidol & $\uparrow$ & Striatum, NAc Core and Shell & $\begin{array}{l}\text { Polese et al., 2002; Dell'aversano et al., 2009; } \\
\text { lasevoli et al., 2010a,b, 2011; De Bartolomeis } \\
\text { et al., 2015a }\end{array}$ \\
\hline & Acute Haloperidol or Olanzapine & $\downarrow$ & PFC & Fumagalli et al., 2009 \\
\hline & Chronic Haloperidol or Olanzapine & $\downarrow$ & Striatum & Fumagalli et al., 2009 \\
\hline & Acute Lurasidone & $\uparrow$ & Hippocampus, Striatum & Luoni et al., 2014b \\
\hline & Chronic Aripiprazole & $\uparrow$ & $\begin{array}{l}\text { PFC, } \\
\text { Striatum, } \\
\text { Hippocampus }\end{array}$ & Luoni et al., 2014a \\
\hline & $\begin{array}{l}\text { Chronic Asenapine or Olanzapine or } \\
\text { Haloperidol }\end{array}$ & $\downarrow$ & PFC & Buonaguro et al., $2017 \mathrm{a}$ \\
\hline & Chronic Lurasidone & $\uparrow$ & PFC, Hippocampus, and Striatum & Luoni et al., 2014b \\
\hline Homer1a & Acute Asenapine or Olanzapine & $\uparrow$ & $\begin{array}{l}\text { PFC, } \\
\text { Lateral Striatum, } \\
\text { NAc }\end{array}$ & lasevoli et al., 2010a; De Bartolomeis et al., 2015a \\
\hline
\end{tabular}


TABLE 1 | Continued

\begin{tabular}{|c|c|c|c|c|}
\hline Gene & Drug & $\begin{array}{l}\text { Effect on gene } \\
\text { expression }\end{array}$ & Brain region & References \\
\hline & Acute Clozapine & $\uparrow$ & NA & Polese et al., 2002 \\
\hline & Acute Haloperidol, but not Clozapine, & $\uparrow$ & Lateral Striatum & Cochran et al., 2002 \\
\hline & Acute Risperidone & $\uparrow$ & $\begin{array}{l}\text { Lateral Striatum, } \\
\text { NAc }\end{array}$ & lasevoli et al., 2010a \\
\hline & Acute Sertindole & $\uparrow$ & PFC & lasevoli et al., 2010b \\
\hline & Acute Ziprasidone & $\uparrow$ & Striatum & lasevoli et al., 2011 \\
\hline & Sub-chronic Amisulpiride & $\uparrow$ & $\begin{array}{l}\text { PFC, } \\
\text { Striatum }\end{array}$ & De Bartolomeis et al., 2016 \\
\hline & Chronic Haloperidol & $\uparrow$ & Striatum & lasevoli et al., 2010b; Buonaguro et al., 2017a \\
\hline & $\begin{array}{l}\text { Chronic Olanzapine or high dose } \\
\text { Asenapine }\end{array}$ & $\uparrow$ & Striatum & Buonaguro et al., 2017a \\
\hline \multirow[t]{9}{*}{$B D N F$} & Acute Haloperidol & $\downarrow$ & Thalamus & Robbins et al., 2008 \\
\hline & Acute or chronic Clozapine & $n c$ & Cortex, Hippocsmpus & Linden et al., 2000 \\
\hline & $\begin{array}{l}\text { Acute and chronic Clozapine or } \\
\text { Haloperidol }\end{array}$ & $\downarrow$ & Hippocampus & Lipska et al., 2001 \\
\hline & Chronic Aripiprazole & $\downarrow$ & Hippocampus & Luoni et al., 2014a \\
\hline & Chronic Clozapine & $\uparrow$ & Whole rat brain & Kim et al., 2012; Rizig et al., 2012 \\
\hline & $\begin{array}{l}\text { Chronic Haloperidol or high-dose } \\
\text { Risperidone }\end{array}$ & $\downarrow$ & Hippocampus & Chlan-Fourney et al., 2002; Parikh et al., 2004 \\
\hline & Chronic Lurasidone & $\uparrow$ & $\begin{array}{l}\text { PFC, } \\
\text { Hippocampus }\end{array}$ & Fumagalli et al., 2012 \\
\hline & Chronic Olanzapine or Clozapine & $\uparrow$ & Hippocampus & Bai et al., 2003 \\
\hline & Chronic Quetiapine & $\uparrow$ & Hippocampus & Park et al., 2006 \\
\hline \multirow[t]{2}{*}{ Npas4 } & Acute Lurasidone & $\downarrow$ & Hippocampus & Luoni et al., 2014b \\
\hline & Chronic Aripiprazole & $\uparrow$ & Dorsal Hippocampus & Luoni et al., 2014a \\
\hline \multirow[t]{2}{*}{ Narp } & Acute Clozapine & $\downarrow$ & Striatum & Robbins et al., 2008 \\
\hline & Acute Haloperidol & $\downarrow$ & Thalamus & \\
\hline
\end{tabular}

$\uparrow$, Gene expression is up-regulated; $\downarrow$, Gene expression is down-regulated; NAc, Nucleus accumbens; PFC, Prefrontal cortex, FC Frontal cortex.

significantly higher SMR in dorso-lateral than in the dorsomedial region of the caudate-putamen (Bubser and Deutch, 2002). Numerous studies have correlated the matrix with motor behavior and stimulus-response memory consolidation, while the striosome has been related to reward mechanisms (White and Hiroi, 1998). Thus, the striosome/matrix architecture of the striatum has been proposed as a morphological substrate for a modular reinforcement-learning model (Amemori et al., 2011). Moreover, it has been suggested that the striosome may be linked to cognition, since it receives prominent inputs from association cortex (Bubser and Deutch, 2002).

Differences in the putative clinical profile of typical and atypical antipsychotics may be inferred by their specific spatial pattern of $c$-fos induction.

D2Rs blockade by antipsychotics has been demonstrated to relieve the inhibition of adenylyl cyclase and activate the PKA, which in turn is responsible for the phosphorylation of CREB. Phospho-CREB may then interact with the cAMP response element (CRE) site in the promoter region the $c$-fos gene (Benito and Barco, 2015). Considering that all the antipsychotics, with few exceptions, are multireceptor-binding drugs, it is conceivable that other receptors beyond D2Rs could be responsible and/or contribute to $c$-fos activation.
Nevertheless, mapping $c$-fos expression to unravel antipsychotics differential functional impact on brain areas has some limitations. In fact, although antipsychotics show specific topographical patterns of $c$-fos induction according to their typical/atypical characteristics, the expression of $c$-fos in neurons has been described to be coupled to multiple different extracellular stimuli, hence it is difficult to attribute a specific c-fos "fingerprint profile" to each antipsychotic compound. $C$-fos induction may help to detect where and when a brain area is activated by a certain compound, but it gives little information on which is the specific intracellular pathway stimulated by this compound. Thus, the data obtained by $c$-fos induction in response to antipsychotics need to be integrated with by other IEGs induction with a more direct function in the synapse.

\section{$\triangle F o s B:$ An IEG with a Dual Function}

$\triangle F O S B$ is a splicing variant of the FosB gene, a member of the FRA family (Fos Related Antigens). Depending on its expression kinetics, the role of $\triangle$ FosB can be either of transcription activator or repressor, with lower levels leading to short-term gene repression and higher levels leading to long-term gene activation (Nestler, 2015). 
Among the main target genes of $\triangle F o s B$ there are: metabotropic Glutamate Receptors subtype 2 (mGluR2), Dynorphin, the nuclear factor $k B$ (NFkB) and $c$-fos.

$\triangle F o s B$ gene is rapidly induced in the dorsal striatum and nucleus accumbens dynorphin-expressing Medium-sized Spiny Neurons (MSNs) - two neural populations closely involved into reward and addiction-in response to addictive drugs such as cocaine and amphetamines (Maze and Russo, 2010). $\triangle F O S B$ induction is reported to not undergo tolerance, thus its accumulation in those brain regions is quite stable after repeated administrations. Moreover, unlike other IEGs, $\triangle F o s B$ levels in striatum and nucleus accumbens are quite stable across the time, and remain up-regulated for weeks after the initial stimulus (Nestler, 2005).

\section{$\Delta F o s B$ Modulation by Antipsychotics}

$\triangle F o s B$ expression has been also studied in response to antipsychotic drugs. Indeed, chronic treatment with haloperidol may enhance the expression of $\triangle F o s B$ in the ventral, medial, and dorso-lateral aspects of the striatum (Rodriguez et al., 2001). Clozapine, on the other hand, may induce $\Delta$ FosB-like immunoreactivity not only in the ventral striatum but also in the prefrontal cortex and lateral septum, with a weaker impact on dorso-lateral striatum, whereas risperidone and olanzapine only weakly induce $\triangle F o s B$ in striatum (Vahid-Ansari et al., 1996; Atkins et al., 1999). Given the long-term standing of $\triangle F o s B$ activation in response to dopaminergic drugs, this IEG has been proposed as a specific marker to identify neurons undergoing prolonged activation in chronic paradigms (Dietz et al., 2014).

\section{C-Jun \\ C-Jun Regulation and Schizophrenia Preclinical Modeling}

C-Jun is a TF that dimerizes with Fos family members to form the AP-1 complex. As an IEG, c-Jun plays a pivotal role in neuronal apoptosis and neurons survival (Jochum et al., 2001). Various extracellular stimuli may activate the JNK (c-jun kinase)/CJun cascade, including stress, ischemia, and stroke, seizures, learning and memory, axonal injury (Raivich and Behrens, 2006). Interestingly, a potential indirect role for c-Jun in a preclinical model of schizophrenia pathophysiology has been recently highlighted by investigating attentive function in mice

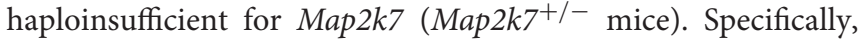
Map2k7 encodes for MKK7 (MAP kinase kinase 7), which is responsible for the activation of JNK. The reduction of Map $2 k 7$ function has been found to be associated to cognitive deficits in mice (Openshaw et al., 2017).

Moreover, putative links between $c$-Jun and schizophrenia are suggested in preclinical models by several findings showing that both psychotomimetic and antipsychotic drugs modulate $c$-Jun levels in brain regions implicated in schizophrenia. Indeed, c-Jun expression is affected by $\mathrm{N}$ methyl-D-aspartate (NMDA) receptor antagonists such as MK-801 (Gerlach et al., 2002) mimicking a preclinical model of schizophrenia.

\section{C-Jun Modulation by Antipsychotics}

C-Jun expression has been demonstrated to be modulated by antipsychotics. Chronic treatment with clozapine or haloperidol induces long-lasting c-Jun expression in the rat forebrain and basal ganglia even after a washout period (Kontkanen et al., 2002). A recent proteomic quantification analysis has demonstrated that chronic haloperidol administration in rodents may modulate the expression of 216 proteins in hippocampus, including c-Jun N-terminal kinase signaling (Schubert et al., 2016). In contrast, acute haloperidol or clozapine treatment have been shown to exert no effects on c-Jun expression, although both these treatments produce clear changes in the expression of several other IEGs, including $c$-fos and other Jun-family members (MacGibbon et al., 1994). These data suggest that antipsychotic drugs may play different roles in modulating apoptosis-related molecules, and are coherent with the findings suggesting that typical and atypical antipsychotics may differentially affect putative neuroprotection (Jarskog, 2006; Nandra and Agius, 2012).

Thus, taken together, the findings reviewed until now may suggest that:

1) $c$-fos activation could represent a valuable tool to understand how antipsychotics recruit different brain regions;

2) $c$-fos activation mirrors, with acceptable approximation, the involvement by antipsychotics of motor vs. limbic brain regions based on the different receptor profile of the antipsychotic taken into account;

3) Based on the emerging role of $c$-fos polymorphisms in schizophrenia, it will be of interest to investigate whether and how the association with $c$-fos and related genes may have any causative role in the pathophysiology of the disorder;

4) $\triangle F o s B$ expression is probably of higher interest to explore the long-term effects of antipsychotics action;

5) Despite being less investigated compared to other IEGs, $c$ Jun stands by itself for the recent proteome findings linking its signaling pathway to antipsychotics action in a network fashion.

\section{NUCLEAR RECEPTORS (NUR) SUPERFAMILY: ANTIPSYCHOTICS MODULATION OF DOPAMINERGIC NEURODEVELOPMENTAL FACTORS}

\section{The Nur Superfamily: Role in Dopamine System Development and Modulation by Antipsychotics}

Nurr1, NGFI-B/Nur77 (Nerve Growth Factor Inducible-B) and Nor1 (neuron-derived orphan receptor-1) are members of the NR4A (Nuclear Receptors 4A) subgroup of nuclear orphan receptors superfamily, which includes a wide variety of TFs, such as retinoid hormone receptor, steroid, and thyroid hormone receptor (Law et al., 1992; Maxwell and Muscat, 2006). All the three Nur members share overlapping sequences and play essential roles in the development of the dopaminergic system. The three members of NR4A subgroup have been described to 
respond to several physiological and physical stimuli, such as prostaglandins, stress, hormones, neurotransmitters, membrane depolarization, and magnetic fields (Katagiri et al., 1997; Tetradis et al., 2001; Kagaya et al., 2005) in an IEG-like fashion. Thus, the immediate-early response of $N R 4 A$ genes to environmental stimuli is an essential feature of these nuclear receptors, which has been extensively studied with regard to their correlation with dopaminergic system (Campos-Melo et al., 2013).

Nurr1 is mainly expressed in the central nervous system, especially in midbrain dopaminergic neurons of the substantia nigra and the ventral-tegmental area (VTA; Backman et al., 1999). Several studies have reported that Nurr1 plays an essential role in the development and differentiation of dopaminergic neurons of the midbrain. Given its role in dopamine neurons development, Nurr1 has been implicated in neuropsychiatric disorders in which dopamine system is dysfunctional, such as schizophrenia. Recent studies reported that Nurr1 gene may be considered as a possible candidate to explore the dysfunctional gene-environment interaction that is considered to be at the basis of these disorders. Indeed, two missense mutations in the gene have been found in schizophrenia patients (Buervenich et al., 2000) and may be directly related to their impaired cognitive performances (Ancin et al., 2013).

Heterozygous deletion of Nurr1 gene in mice has been recently considered as a possible animal model of schizophrenia, since these animal display elevated dopamine levels in basal ganglia (Moore et al., 2008), and characteristic dysfunctional behaviors resembling psychotic symptoms in humans (Rojas et al., 2007).

Similarly, also Nur77 has been implicated in the pathophysiology of schizophrenia. Indeed, reduced levels of Nur77 have been detected in prefrontal cortex of post-mortem schizophrenia patients (Xing et al., 2006). Moreover, single nucleotide polymorphisms of Nur77 gene have been associated with elevated risk of tardive dyskinesia (TD) in schizophrenia patients (Novak et al., 2010).

Given the direct correlation between Nur IEGs and the development of dopaminergic system, a large body of evidence has been set up on the regulation of NR4A IEGs in response to dopamine manipulation.

\section{Nur IEGs Modulation by Antipsychotics}

The first studies with antipsychotics demonstrated that Nur IEGs response to these drugs may resemble that of $c$-fos in rat brain. For instance, typical and atypical antipsychotics induce differential patterns of Nur IEGs expression. Indeed, acute haloperidol administration pronouncedly increases Nur77 expression in dorso-lateral striatum, whereas clozapine induces this gene preferentially in prefrontal cortex and in the shell of the nucleus accumbens (Beaudry et al., 2000). Moreover, haloperidol selectively increases Nur77 dorsolateral striatal expression in enkephalin-containing neurons, which are MSN neurons mostly expressing D2Rs, whose up-regulation has been correlated to extrapyramidal symptoms induced by neuroleptics. In addition, the same report showed that chronic haloperidol administration provokes a further increase in Nur77 dorso-lateral striatal expression, whereas chronic clozapine reduces Nur77 gene expression below basal values in prefrontal and accumbal areas.
To confirm the role of Nur77 in acute neuroleptic-induced EPSEs, later studies demonstrated that in Nur77-deficient mice haloperidol-induced acute catalepsy was completely abolished, as well as the Nur77 mRNA overexpression in enkephalinpositive neurons (Ethier et al., 2004). Therefore, similarly to $c$-fos expression, Nur IEGs modulation by antipsychotics may be used as a tool to dissect the propensity of a neuroleptic drug to induce extrapyramidal side effects.

Some other significant similarities with $c$-fos have been shown in the regulation of NR4A members expression by antipsychotics. Indeed, Maheux and coworkers demonstrated that Nur IEGs may be induced by typical antipsychotics selectively in striatal areas that control motor functions, whereas atypical antipsychotics induced Nur IEGs expression in limbic areas (Maheux et al., 2005). This induction pattern tightly correlates with D2Rs affinity by each antipsychotic in striatum and with D2/D3Rs affinity in the nucleus accumbens. The same research group further demonstrated that selective serotonergic and adrenergic drugs may modulate haloperidol-induced Nur IEGs expression, suggesting that also serotonin neurotransmission may take part into the differential patterns of regulation of these genes by typical and atypical antipsychotics (Maheux et al., 2012).

There are substantial differences in response to antipsychotics between the different members of Nur family: both Nur77 and Nor1 are de novo induced in dopamine neurons and striatal areas, whereas Nurr1 is basally expressed in VTA and substantia nigra and its expression is enhanced by antipsychotics (Eells et al., 2012).

Regarding the mechanisms involved in Nur regulation by antipsychotics drugs and D2Rs antagonists, it has been demonstrated that, at least for Nur-77 and Nor-1, the induction/increase in mRNA are depending by both mitogenassociated and extracellular signal-regulated kinases (MEK) and Protein Kinase C (PKC) in the case of Nurr-77 and by PKC only in the case of Nor-1 (Bourhis et al., 2008).

Hence, Nur IEGs modulation by antipsychotics appears to provide a complementary information as compared to $c$-fos expression patterns, thereby contributing to shed further light on the impact of these drugs not only on brain areas that are targeted by dopamine neurons, but also on areas in which dopamine neurons localize. Thus, although still elusive, the analysis of Nur IEGs modulation by antipsychotic drugs may be a further tool to dissect the mechanisms of action of these compounds on dopamine systems, as well as it may help to further clarify the molecular mechanisms by which these drugs alter locomotor activity in animal models and in humans.

\section{MODULATION BY ANTIPSYCHOTICS OF IEGs INVOLVED IN SYNAPTIC PLASTICITY: PUTATIVE TARGETS FOR COGNITIVE DEFICITS IN PSYCHOSIS}

Abnormal synaptic plasticity may account for several cognitive and behavioral processes that are dysfunctional in schizophrenia. Cognitive impairment, indeed, is a striking clinical aspect of psychotic illnesses, is detectable before the onset of other 
symptoms, and it is considered among the best predictors of long-term lifetime functioning (Green, 1996).

Since long-term neural plasticity requires protein synthesis, IEGs expression could be considered as a necessary step in synaptic architecture remodeling. For several IEGs involved in these processes, a role in the pathophysiology of psychosis has been proposed. In the following section, we will summarize how antipsychotic therapy may impact these genes expression.

\section{Egr1: How Antipsychotics Impact Synaptic Processes Underpinning Memory and Learning \\ Egr1 Regulation and Involvement in Synaptic Plasticity}

The Egr-family consists of four highly homologous zinc-finger TFs: Egr1 (Early growth response gene 1, also named NGFIA, zif-268, Krox 24), Egr2 (Krox 20), Egr3 (PILOT), and Egr4 (NGFI-C).

Egr1 is an immediate-early gene (IEG) coding for a TF and is constitutively expressed in the cortex, amygdala, striatum, nucleus accumbens, hippocampus, and cerebellum (Beckmann and Wilce, 1997). Several stimuli have been demonstrated to induce Egr1 overexpression in these areas, such as seizures, ischemia, stress, and drug administration (Hughes and Dragunow, 1995). Many of these stimuli share the common feature of elevating intracellular calcium (Ca2+; Ghosh et al., 1994). Pharmacological stimuli provoking massive Ca2+ influx in neurons have been described to increase Egr1 expression (Shirayama et al., 1999; Zhou et al., 2009; Gangarossa et al., 2011). Egr1 activity has been related to the transcription of other IEGs involved in synaptic plasticity, above of all Arc (Penke et al., 2011). In turn, Egr1 expression may be under the control of other genes, such as the Brain-Derived Neurotrophic Factor (BDNF; Robinet and Pellerin, 2011) and other proteins involved in intracellular signaling (Lam et al., 2009).

Egrl synaptic action has been related to neural plasticity, in particular to synaptic processes leading to memory consolidation and behavioral adaptations (Davis et al., 2003; Okada et al., 2015) Intriguingly, dysfunctions in the postsynaptic machinery deputed to control memory and learning processes have been recently related to cognitive impairment in major neuropsychiatric disorders, such as schizophrenia (Grant, 2012). In paradigms of instrumental learning, Egrl is markedly induced in frontal and cingulate cortices (Hernandez et al., 2006; Snyder et al., 2012). Furthermore, Egr1 plays a pivotal role in maintaining the late phase of LTP in hippocampus, in dorsal caudate-putamen (Gill et al., 2007), and in the retrosplenial cortex (Amin et al., 2006). Egr1, along with BDNF, also appears to play a role in retrieval-dependent plasticity, a mechanism accounting for the modification of previously consolidated memories being recalled (Lee, 2010). Moreover, it has been shown that Egr1, together with BDNF (Barnes et al., 2012), Homerla and Arc, has a relevant role in the mechanisms of the initial consolidation, reconsolidation and extinction of fear- and anxiety-related memory (Lonergan et al., 2010; Maddox et al., 2011; Cheval et al., 2012).
Dopamine and glutamate systems have been implicated in synaptic processes involved in memory consolidation [e.g., longterm Potentiation (LTP) and long-term depression (LTD)], and several studies reported that Egrl expression may be modulated by stimuli affecting either glutamate or dopamine neurotransmission (Li et al., 2016).

\section{Egr1 Modulation by Antipsychotics}

Several antipsychotics (e.g., clozapine) modulate synaptic proteins related to memory formation in hippocampus and improve cognitive tasks in animal models of pharmacological NMDA receptor hypofunction (Ozdemir et al., 2012). With regard to dopamine, Egr1 gene and protein expression are modulated by both acute and chronic antipsychotic treatments in preclinical settings (Wheeler et al., 2014; De Bartolomeis et al., 2015a).

Clinical studies have reported an abnormal regulation of Egr1 in schizophrenia patients compared to normal controls. Specifically, post-mortem gene expression studies and in vivo plasma detection have demonstrated that Egrl is downregulated in prefrontal cortex of schizophrenia patients in a fashion that is directly correlated with decrease in GAD1 (glutamate decarboxylase 1, the enzyme that is responsible for GABA production), and plasma levels were reduced, therefore supporting the view that Egr1 may be a potential biomarker of the disease (Kimoto et al., 2014). Interestingly, an association of SNPs in Egr3 and Arc with schizophrenia has been proposed as a biological pathway of environmentally responsive, synaptic plasticity-related, schizophrenia risk genes (Huentelman et al., 2015).

Given the potential role of this IEG in schizophrenia pathophysiology and treatment, it is to mention that early studies have also compared Egrl modulation by antipsychotics to the modulation of the other well-known IEG $c$-fos, showing that these two IEGs, although similarly impacted by typical and atypical antipsychotics in cortex and striatum, displayed some substantial differences. Haloperidol has been reported to induce both $c$ fos and Egr1 expression in striatum, whereas clozapine may induce Egr1 but not c-fos expression in the same region. Both antipsychotics may induce the expression of both these genes in nucleus accumbens (Nguyen et al., 1992; MacGibbon et al., 1994).. Subsequent findings further demonstrated a differential response of Egrl from $c$-fos also in chronic antipsychotics administration paradigms. Egrl, indeed, is robustly downregulated in locus coeruleus and prefrontal cortex of olanzapine chronically administered rats, whereas $c$-fos expression remains up-regulated (Verma et al., 2007). Moreover, chronic haloperidol may increase cortical Egr1 expression, whereas it decreases $c$-fos expression in this area (Verma et al., 2007).

Targeted experiments have demonstrated that Egr1 modulation by antipsychotic drugs may be directly related to the synaptic functions of drug-associated memory consolidation. For instance, high D2R-blocking antipsychotics (e.g., sulpiride) may prevent the increase in Egrl expression induced by acute cocaine administration in striatum, but not in the cortex (Daunais and McGinty, 1996). The modulation of Egr1 and other activity-regulated genes such as Arc and Npas4 has been studied 
in rodents after the administration of the novel antipsychotic lurasidone, which is characterized by a multi-receptor profile and particularly by a potent 5 -HT7 receptor antagonism, considered beneficial for mood and cognition (Luoni et al., 2014b).

Finally, Egr1 levels of expression have been recently investigated in preclinical settings exploring new therapeutic strategies in schizophrenia beyond current antipsychotic drugs (Gentzel et al., 2015).

However, it should be considered that the dopaminergic regulation of Erg1 is even more complicated by the action of multiple pathways in reciprocal interplay with dopaminergic system. Recent evidence, indeed, demonstrated that $m u$-opioid receptors have also a major implication in psychostimulantinduced sensitization (Shen et al., 2010) and antipsychotic drugs seem unable to prevent methamphetamine-induced striatal overexpression of Egrl in $m u$-opioid receptors knock-out animals (Tien et al., 2010).

Putting together the findings reviewed therein, the role of Egr1 in antipsychotics action appears relevant mainly because it is directly implicated in specific signaling and neuronal plasticity programs related to memory, cognition and executivelike functions in preclinical models. This is a major point, since there is a need to explore new compounds in schizophrenia that may address dysfunctions in the domains of cognitive and negative symptoms, which are poorly affected by currently available antipsychotic agents.

\section{Arc/Arg3.1: Modulation of Long-Term Activity-Dependent Synaptic Efficacy by Antipsychotic Treatments \\ Arc Regulation and Involvement in Synaptic Plasticity: Relevance for Schizophrenia}

As other IEGs, Arc (activity-regulated cytoskeletal-associated protein) also referred to as Arg3.1 (activity-regulated gene homolog 3.1), is expressed at low levels in neurons, especially in the hippocampus. However, Arc levels are relatively higher in cortex, and are directly linked to NMDA receptor activation (Link et al., 1995). Arc shows unique features, since its mRNA may be induced together with other IEGs by neural activation (i.e., single seizures), but differently from other mRNAs-such as Egr1-that remain in the neuron soma, Arc is rapidly translocated to dendritic spines (Wallace et al., 1998). The activity-dependent translocation of $A r c$ requires NMDA receptor activation (Steward and Worley, 2001). Moreover, Arc protein is selectively produced in dendritic spines near the activation site, even in the presence of protein-synthesis inhibitors, thereby indicating that Arc mRNA owns a unique intrinsic signal that permits the activityrelated targeting to stimulated dendrites (Bramham et al., 2010; Steward et al., 2014). The activity-dependent regulation of Arc expression has been extensively studied, thus leading to several findings reporting its involvement in synaptic plasticity and its implication in memory and learning processes, which have been demonstrated to be altered in schizophrenia. Experiencerelated stimuli may potently increase Arc expression in brain areas involved in memory consolidation (Lyford et al., 1995). Indeed, the exploration of new environments strongly induces
Arc expression in hippocampus and cortex (Vazdarjanova et al., 2002). Consistently, Arc knock-out animals fail to form longterm memories for learning tasks, displaying impaired LTP and LTD, but unaltered short-term memory (Plath et al., 2006). A role for Arc in synaptic scaling, a form of homeostatic synaptic plasticity, has been postulated (Gao et al., 2010).

Hence, Arc functions seem to be required for synaptic plasticity processes starting at multiple neurotransmitter receptors, such as alpha-amino-3-hydroxy-5-methyl-4isoxazolepropionic acid (AMPA), NMDA, dopamine, serotonin, acetylcholine, and adrenaline receptors (Chowdhury et al., 2006; Rial Verde et al., 2006).

Dopamine and glutamate are considered among the principal neurotransmitters implicated in memory and learning processes, as well as in schizophrenia pathophysiology in which aberrant salience has been reported. Dopamine has been demonstrated to be pivotal for working memory in rodents and in nonhuman primates (Castner et al., 2004; Rinaldi et al., 2007). Arc response to memory and learning stimuli may account for a direct involvement of this IEG into dopaminergic-dependent mechanisms of memory consolidation, as well as for its implication in dopamine-glutamate subcellular interactions that control synaptic plasticity processes thought to be dysfunctional in the pathophysiology of schizophrenia (Eastwood, 2004; Grant, 2012; Yin et al., 2012). To confirm the role of Arc in synaptic processes of dopamine-dependent memory formation, it has been demonstrated that amphetamines may modulate Arc learning-induced expression in hippocampus (Wiig et al., 2009). Bloomer and coworkers have reported a combined effect of NMDA receptors and D1Rs on Arc expression in hippocampal neurons (Bloomer et al., 2008), as well as a dramatic reduction in Arc expression by dopamine agonists when NMDA receptor blockers are concurrently administrated, thus confirming the role of dopamine-glutamate correct interaction in memory consolidation and the crucial functions of Arc in this process. Arc gene has been reported to be affected by de novo mutations in schizophrenia patients and it is part of an enriched gene set characterized by rare disruptive mutations contributing to the genetic risk for schizophrenia (Fromer et al., 2014; Purcell et al., 2014). Further evidence of an implication of Arc in schizophrenia pathophysiology comes from preclinical studies (Manago and Papaleo, 2017). Disruption of Arc produces deficits in sensorimotor gating, cognitive functions, social behaviors, and amphetamine-induced psychomotor responses in mice that are reminiscent of some features of psychosis (Manago et al., 2016).

\section{Arc Modulation by Antipsychotics}

Arc expression in response to antipsychotic challenges has been extensively investigated, in order to shed further light on the molecular mechanisms involved in antipsychotic-mediated modulation of the synaptic plasticity processes putatively disrupted in schizophrenia.

Early works demonstrated that Phencyclidine (PCP)-induced Arc overexpression in prefrontal cortex and nucleus accumbens may be inhibited by pretreatment with clozapine, olanzapine, and risperidone, but not by haloperidol (Nakahara et al., 2000), thus suggesting that Arc modulation may be useful to dissect 
typical from atypical antipsychotics impact on psychotomimetic drug-induced synaptic dysfunctions. Subsequently, acute administration of both typical and atypical antipsychotics was demonstrated to induce Arc gene expression in striatum, with haloperidol showing a more prolonged effect on Arc induction than olanzapine (Fumagalli et al., 2009). These results have been directly correlated to the degree of D2R blockade induced by each antipsychotic, since a selective D2Rs antagonist, such as raclopride, may induce Arc striatal expression and reduce its cortical expression, whereas a selective D2Rs agonist, such as quinpirole, may reduce Arc striatal expression and has no effects on its cortical expression. Notably, Fumagalli et al. (2009) further demonstrated that a prolonged treatment with haloperidol and olanzapine markedly reduced Arc striatal expression, as well as only olanzapine may reduce the expression of the gene in the cortex.

With regard to cortical and subcortical expression of Arc, work from our laboratory demonstrated that Arc gene expression may be induced by haloperidol, but not by sertindole in the striatum, thus further suggesting that Arc modulation may be tightly related to the tuning of dopamine neurotransmission exerted by each antipsychotic (Iasevoli et al., 2010b). Sertindole shows a milder D2Rs impact than haloperidol in the striatum, with a quite absent blockade of D2 autoreceptors (Valenti and Grace, 2010). The involvement of serotonin 5-HT2A receptors has been demonstrated in Arc cortical modulation, with NMDA receptor function being relevant in these effects, thereby suggesting a crucial role of Arc in synaptic rearrangements induced by combined serotonin-dopamine-glutamate stimuli in the cortex by antipsychotics (Pei et al., 2004).

Arc has been shown to be responsive to acute (with significant increase of the transcript in striatum) and chronic (with prevalent gene expression increases in prefrontal cortex and hippocampus and decreases in striatum) lurasidone treatment, suggesting a region-specific fingerprint of Arc induction (Luoni et al., 2014b). An intra-striatal specificity of Arc activation was detected after acute administration of amisulpride $(35 \mathrm{mg} / \mathrm{kg}$ ) with prevalent increase of the transcript in the medial caudateputamen compared to more pronounced induction in dorsal caudate-putamen by haloperidol $(0.8 \mathrm{mg} / \mathrm{kg}$; De Bartolomeis et al., 2013b). Again, a region-specific induction of Arc protein was detected in the shell of the nucleus accumbens by clozapine (20 mg/kg) compared to haloperidol (1 mg/kg; Collins et al., 2014). Finally, Arc has been instrumental also for exploring the brain region effect of innovative treatment approaches in schizophrenia, such as augmentation strategies to antipsychotics (i.e., minocycline in combination with haloperidol; Buonaguro et al., 2017b).

Direct evidence exist that $A r c$ induction can be responsible for increasing the density and for reducing the width of dendritic spine possibly by a mechanism involving AMPA endocytosis (Peebles et al., 2010).

These data globally suggest that $A r c$ is involved in the neural plasticity mechanisms induced by antipsychotics in distinct brain regions. Arc modulation may be demonstrated to occur before the timing necessary to observe the therapeutic-like effects commonly observed during antipsychotic therapies, possibly suggesting that Arc is potentially relevant in establishing the correct synaptic rearrangements underlying antipsychotic effects. Finally, the recent discovery of Arc subdomains similar to the domain of HIV capsid and its involvement in rapid synaptic functions (possibly derived from the ancestral viral origin) deranged in schizophrenia (Zhang et al., 2015), make this IEG of relevant interest for studying specifically "fast" synaptic changes during antipsychotic treatment.

\section{Homer1a: IEG-Mediated Activity-Dependent Postsynaptic and Architecture Rearrangements in Response to Antipsychotic Treatment The Homer Family and Its Regulation by Dopamine-Glutamate Interaction}

Homer genes encode a family of scaffolding proteins (Homer1, Homer2, Homer3) localized mainly at the glutamatergic postsynaptic density (PSD) of dendritic spines, where they act as multifunctional adaptors among multiple transduction pathways. Homer1 gene encodes both constitutively expressed long transcripts (Homer $1 b / c)$ and for a short isoform named Homerla, which is induced in an IEG-like fashion (Bottai et al., 2002). Within the PSD, Homer proteins couple to metabotropic and indirectly ionotropic glutamatergic receptors, bridging both to intracellular receptors, such as the inositol 1,4,5-trisphosphate receptor (IP3Rs), the ryanodine receptor (RyR), and to other PSD scaffolding proteins, such as Shank (De Bartolomeis and Iasevoli, 2003; Gao et al., 2013). When induced, Homer1a protein disassembles constitutive Homers clusters by acting as a "dominant negative," thus modifying synaptic architecture and Ca2+ homeostasis (Shiraishi-Yamaguchi and Furuichi, 2007). Several studies demonstrated a pivotal role of Homerla in modulating the crosstalk between PSD proteins involved in mechanisms underlying synaptic plasticity, such as receptor localization, distribution and internalization (Iasevoli et al., 2013). For example, it has been observed that Homerla is rapidly up-regulated during enhancement of network activity and promotes the agonist-independent signaling of group I mGluRs that may in turn scale down the expression of AMPA receptors (Hu et al., 2010). To note, in animal models, impaired homeostatic scaling has been reported in a NMDA receptorblocking experimental paradigm, which mimics psychotic states (Wang and Gao, 2012). Based on the crucial role of Homerla in synaptic plasticity, dysfunctions in its fine-tuning activity have been closely related to psychiatric disorders (Luo et al., 2012). Homer1 polymorphisms have been associated with schizophrenia (Spellmann et al., 2011) and cocaine addiction (Dahl et al., 2005) and Homer1 knock-out mice exhibit a behavioral phenotype resembling psychotic disorders (Szumlinski et al., 2005), as well as Homer2 proteins have been implicated in regulating addiction to cocaine in animal models (Szumlinski et al., 2004). A fine-tuned modulation of Homerla expression has been associated to a number of mechanisms of adaptation to different environmental and pharmacological stressors: for instance, Homer 1a overexpression in cortical structures may facilitate the ability to cope with stress (Szumlinski et al., 2006). Finally, 
Homer1 gene variants have been associated with neuropsychiatric disorders such as psychosis in Parkinson disease (De Luca et al., 2009), major depression pathophysiology (Serchov et al., 2016), and response to lithium treatment (Benedetti et al., 2018).

\section{Homer1a Modulation by Antipsychotics}

Dopamine indirect agonists, such as cocaine or amphetamines, may induce Homerla expression in striatum and nucleus accumbens with peculiar patterns of expression (Yano and Steiner, 2005; Zhang et al., 2007). Moreover, although the acute administration of cocaine may induce strong Homerla expression in cortico-striatal circuits, these effects are abolished after 2 or 3 weeks of withdrawal (Ghasemzadeh et al., 2009), suggesting a crucial role of Homerla in cocaine-mediated synaptic plasticity. Specific studies demonstrated that dopamine agonists-dependent Homer1a induction is regulated by selective activation of D1Rs but not D2Rs (Yamada et al., 2007). Recent findings by our group have demonstrated that this IEG may be differentially induced by antipsychotics, with a peculiar pattern of expression depending on the degree of D2R blockade by each compound and on the selective brain area in which each antipsychotic exerts its functions (Tomasetti et al., 2007). Haloperidol has been demonstrated to induce Homerla expression specifically in dorso-lateral regions of caudate-putamen and in the core of the nucleus accumbens, a feature that is consisting with the propensity of this compound to provoke EPSE in humans at high dosages (Ambesi-Impiombato et al., 2007). By contrast, atypical antipsychotics (i.e., aripiprazole, clozapine, olanzapine, quetiapine, ziprasidone) preferentially induce Homerla gene expression in ventro-medial regions of caudate-putamen and in the shell of the nucleus accumbens, whlich are brain regions implicated in the control of reward and motivated behavior (Tomasetti et al., 2007; Iasevoli et al., 2009). It is worthy to note that each antipsychotic compound has been described to induce a specific pattern of Homerla expression that is tightly related to its degree of D2R blockade, being this latter essential in order to stimulate Homerla induction (Iasevoli et al., 2011). Homerla has been shown to be induced differentially also by the administration of the same antipsychotic at different doses: for example, it has been demonstrated that increasing doses of haloperidol not only increase the intensity (i.e., higher autoradiographic signal level) of gene expression in brain regions originally activated by the same drug at lower doses, but also induce the expression of the IEG in new brain regions (i.e., ventral caudate; De Bartolomeis et al., 2015a). Moreover, Homer1a modulation has been described in cortical areas only by antipsychotics that may impact serotonergic neurotransmission (Iasevoli et al., 2010a,b). Recent studies, indeed, demonstrated that cortical Homerla induction by antipsychotics may resemble that by selective serotonergic agents, and when co-administered, haloperidol plus a selective serotonergic reuptake inhibitor antidepressant (SSRI, i.e., citalopram or escitalopram) may induce a pattern of Homerla cortical expression tightly resembling the pattern by atypical antipsychotics (Dell'aversano et al., 2009; Serchov et al., 2016). Further evidence demonstrated that Homer genes may be involved also in synaptic rearrangements induced by combined mood-stabilizing/antipsychotic treatment (Tomasetti et al., 2011) and in switching between antipsychotics (De Bartolomeis et al., 2016). In sum, regarding the mechanism by which antipsychotics increase Homerla and in turn may modify dendritic spine, D2Rs antagonism or partial agonism is the major candidate, possibly with a mechanism CRE-related, even if other pathways (i.e., ERK-related) can also be involved. Homerla induction may have a pivotal role in remodeling the dendritic spine, modifying the availability of the constitutive isoform (Homer1b/c) that is involved in a transient spine increase that is eventually followed by more persistent modification by recruitment of other postsynaptic proteins such as PSD-95 (Meyer et al., 2014).

Altogether, these data confirm the role of Homers in the fine modulation of synaptic processes triggered by psychotropic drugs also when co-administered with antidepressant or mood stabilizers, posing the bases for further understanding the molecular correlates of real-world clinical psychopharmacology. The pattern of Homer inducible isoform expression may therefore provide a specific "fingerprint" profile of psychopharmacologic treatments, which could be a useful tool for elucidating glutamate-dopamine interactions putatively dysfunctional in schizophrenia pathophysiology.

\section{BDNF: Neurotrophic Control of Synaptic Plasticity by Antipsychotic Treatment BDNF Activity-Dependent Modulation and Synaptic Plasticity}

BDNF belongs to a subfamily of neurotrophins that includes the nerve growth factor (NGF), the neurotrophin-3 (NT3), and the neurotrophins 4 and 5 (NT4/5). Several studies have demonstrated that neuronal activity, or in general stimuli that increase intracellular levels of $\mathrm{Ca} 2+$, may induce BDNF expression in neurons (Aicardi et al., 2004; Aid et al., 2007). Specifically, exon IV transcription seems to be directly controlled by neural activation (Chen et al., 2003). Moreover, the rapid activity-dependent increase in $B D N F$ mRNA after a stimulus and its independence from the most common TFs (such as AP-1), have suggested that $B D N F$ may be rather considered a "secreted IEG," because of its immediate-early response fashion that does not involve new protein synthesis (Lauterborn et al., 1996; Xu et al., 2000; Gartner et al., 2006). The activity-dependent modulation of BDNF, as well as the BDNF-dependent master control of synaptic functions, has increased the attention on this molecule in synaptic plasticity. Several reports, indeed, demonstrated that BDNF plays a crucial role in both early and late phases of hippocampal LTP (Pang and Lu, 2004; Rex et al., 2006; Yano et al., 2006), as well as suggest a pivotal role of BDNF also in long-term memory processes (Lu et al., 2008; Waterhouse and Xu, 2009). BDNF exerts also a regulatory role on other IEGs expression: $A r c$ has been found to be a key molecular effector of $B D N F$ action in synaptic plasticity since its expression is necessary for stable LTP formation after BDNF levels increase in both in vivo and in vitro experiments (Messaoudi et al., 2007; Wibrand et al., 2012; Panja et al., 2014).

As in the case of the IEGs considered before, several studies reported a direct correlation between dopamine 
neurotransmission and BDNF functions. Indeed, BDNF null mice have been demonstrated to display a reduced number of dopaminergic neurons in the substantia nigra (Baquet et al., 2005). Moreover, BDNF is crucial for a correct D3Rs expression in nucleus accumbens, and thereby it seems involved in pathological conditions in which these receptors have been reported as dysfunctional, such as Parkinson's disease or antipsychotic-induced TD (Guillin et al., 2001; Zai et al., 2009).

\section{BDNF, Schizophrenia, and Modulation by Antipsychotics}

Given the tight association of BDNF functions with activitydependent dopamine-mediated synaptic plasticity, it is not surprising that several studies have highlighted the role of $B D N F$ in the pathophysiology of neuropsychiatric disorders in which dopamine-glutamate interaction is dysfunctional, such as schizophrenia. The rs6265 single nucleotide polymorphism (SNP) - which leads to the Val66Met substitution at codon 66has been reported to alter the activity-dependent trafficking and release of BDNF in neurons (Chen et al., 2004). This SNP has been associated with schizophrenia in Chinese and Caucasian populations (Hong et al., 2003; Neves-Pereira et al., 2005; Chen et al., 2006). Moreover, SNP homozygotes display reduced hippocampal cortex (Takahashi et al., 2008). In post-mortem studies, a decrease in BDNF levels in frontal cortices (Weickert et al., 2003) and an increase in hippocampus have been reported in schizophrenia patients (Iritani et al., 2003). Moreover, in the assessment of 825 patients for Positive and Negative Syndrome Scale in a single marker analysis, the BDNF rs10835210 mutant A allele was significantly associated with schizophrenia. Haplotype investigation detected higher frequencies of haplotypes with the mutant A allele of the rs10835210 in schizophrenia patients than in controls (Zhang et al., 2016). In addition, schizophrenia patients showed lower basal serum levels of BDNF as compared to healthy subjects (Grillo et al., 2007; Green et al., 2011; Fernandes and Chari, 2016).

Association studies have further suggested that BDNF could be involved in both susceptibility to schizophrenia and in clinical symptom severity. Regarding the role of $B D N F$ in the onset and evolution of psychosis, it is of interest that the expression of the two forms of BDNF receptors (active TrkB-FL and inactiveTrkBT1) in Peripheral Blood Monocyte Cells (PBMCs) of first episode psychotic patients showed modifications according to the trajectory of the disease, with TrkB-FL expression increasing by 1 year after diagnosis and TrkB-T1 expression decreasing. Notably, the TrkB-FL/TrkB-T1 ratio increased in the nonaffective psychosis group only (Martinez-Cengotitabengoa et al., 2016). Multiple studies have assessed the effects of antipsychotic treatments on BDNF expression in preclinical models, as well as of BDNF serum levels in treated schizophrenia patients. Early studies demonstrated that the acute blockade of NMDA receptors may decrease $B D N F$ expression in hippocampus and cortical areas, whereas it may increase its expression in limbic cortex (e.g., entorhinal cortex), and these effects may be not reversed by the administration of haloperidol (Castren et al., 1993). Further studies have confirmed the enhancement of BDNF expression in entorhinal cortex by NMDA receptor-blocking drugs (i.e., MK-801), these effects being contrasted by a pretreatment with haloperidol or clozapine (Linden et al., 2000). However, the sole acute or chronic clozapine treatment did not affect BDNF mRNA levels (Linden et al., 2000). Starting from the assumption that antipsychotic treatment could be correlated to neurotrophic actions in brain areas affected in schizophrenia, Angelucci et al. (2000) reported that chronic treatment with haloperidol or risperidone may decrease BDNF expression in hippocampus, frontal and occipital cortices, also affecting TrkB expression in these areas.

Typical and atypical antipsychotics have differential impact on $B D N F$ expression in distinct brain areas. Chronic haloperidol administration may strongly decrease BDNF hippocampal expression, whereas clozapine and olanzapine have been demonstrated to enhance BDNF expression in the same areas, probably due to $5 \mathrm{HT} 2 \mathrm{~A}$ receptor modulation by these atypical antipsychotics (Bai et al., 2003). Moreover, olanzapine has been successively demonstrated to normalize BDNF hippocampal levels that were reduced by MK-801 administration (Fumagalli et al., 2003). Switching from haloperidol or chlorpromazine to olanzapine, even after a prolonged treatment, may restore $B D N F$ brain level that have been decreased by the previously administered typical antipsychotics (Parikh et al., 2004; Pillai et al., 2006).

Park et al. (2009) reported that ziprasidone, but not haloperidol, may attenuate the decrease in BDNF expression induced by immobilization stress in rats. Aripiprazole, a partial agonist at D2/D3Rs and a functional selective antipsychotic (De Bartolomeis et al., 2015b), has been shown to up-regulate BDNF compared to haloperidol in cell cultures (Park et al., 2009). In early clinical studies, clozapine-treated schizophrenia patients showed higher serum BDNF levels than risperidone-treated patients (Tan et al., 2005). With regard to clinical translation it has been demonstrated that the increase in BDNF serum levels in olanzapine-treated schizophrenia patients may directly correlate with the progressive reduction in positive symptoms (Gonzalez-Pinto et al., 2010).

Regarding the role of BDNF in dendritic spines modulation, is remarkable that multiple lines of evidence point to a brain and cell region specificity of BDNF action.

Specifically, has been shown that BDNF increase in cortical regions may reduce the density of dendritic spines of pyramidal neurons, whereas an increase has been reported for hippocampal pyramidal neurons (Alonso et al., 2004). This finding, considered in the light of antipsychotics modulation of BDNF, could represent a significant morphological underpinning of the association between antipsychotics and changes in brain architecture.

It is questioned if a common ERK-dependent mechanism is involved in the opposite changes observed in cortex and hippocampus.

In summary, the study in preclinical and clinical settings of $B D N F$ response to antipsychotics may help to provide further information on the differential impact of typical vs. atypical antipsychotics on neurons survival and neurogenesis, as well as on putative neurodegenerative mechanisms of dopaminergic systems involved in the pathophysiology of schizophrenia. 
$B D N F$ role as an immediate-early-like gene, TF, and growth factor makes this molecule an exceptional candidate for the investigation of long-term antipsychotic effects on brain structure and function, and the study of the regulation of its expression could provide a molecular tool to predict clinical outcomes of antipsychotic response (Nandra and Agius, 2012).

\section{IEGs RELATED TO GLUTAMATE DEPENDENT PLASTICITY: ANTIPSYCHOTIC TREATMENT EFFECTS ON NPAS 4 AND NARP EXPRESSION}

Npas4 and Narp are IEGs related to glutamate and $\gamma$ aminobutyric acid (GABA) neurotransmission, whose implication in schizophrenia pathophysiology and treatment to date has been explored only by few clinical and preclinical studies.

\section{Npas4: An IEG Selectively Induced by Neuronal Activation}

Npas4 is a TF that belongs to the basic helix-loop-helix-PAS protein family (Moser et al., 2004; Shamloo et al., 2006) that is transcribed in response to excitatory synaptic activity induced in both excitatory and inhibitory neurons. Npas4 is expressed almost exclusively in neurons, it is activated selectively by neuronal activity, and has been demonstrated to control directly the expression of a large number of activity-dependent genes (Coutellier et al., 2012). Recent evidence shows that Npas4 has a regulatory function on the expression of multiple cortical GABAergic markers and that animals null for Npas4 show a decrease in GAD67 and parvalbumin, which can be reverted after the administration of valproic acid (Shepard et al., 2017). Moreover, Npas4 has been involved in stress response and linked to the onset of resistance to L-acetyl carnitine in mice (Bigio et al., 2016). Particularly, this IEG has been shown to regulate the balance between neuronal excitation and inhibition by contributing to the maintenance of the inhibitory pathways. This balance is believed to be pivotal for processing sensory information and for cognitive functioning, while an imbalance between inhibitory and excitatory synapses has been associated with multiple developmental disorders such as schizophrenia. Not surprisingly, it has been recently published the first study that investigated Npas4 expression after antipsychotic administration in rodents. Indeed, the IEG has been demonstrated to be downregulated acutely, but not chronically, in the cortex by the novel antipsychotic lurasidone $(10 \mathrm{mg} / \mathrm{kg})$ at the dose demonstrated to be effective in animal models of schizophrenia (Luoni et al., 2014b).

\section{Narp: An IEG Secreted by Pyramidal Neurons}

Narp (Neuron activated regulated pentatraxin) is an AMPA receptor binding protein with the peculiarity to be secreted by pyramidal neurons onto parvalbumin interneurons and whose gene is rapidly transcribed and regulated by physiological synaptic activity (O’brien et al., 1999, 2002; Chang et al., 2010;
Lee et al., 2017). Functional studies suggest that Narp promotes neuronal migration and dendritic outgrowth with a potency comparable to neurotrophins and growth factors (Tsui et al., 1996; Doyle et al., 2010). Narp is a direct transcriptional target of BDNF. Intriguingly, acute BDNF withdrawal may promote downregulation of Narp, whereas transcription of Narp is greatly enhanced by BDNF (Mariga et al., 2015). Furthermore, it has been demonstrated that BDNF directly regulates Narp to mediate glutamatergic transmission and mossy fiber plasticity (Mariga et al., 2015). Hence, Narp serves as a significant epistatic target of BDNF to regulate synaptic plasticity during periods of dynamic activity. Recently, a close association between Narp expression and schizophrenia pathophysiology has been suggested. In a post-mortem study conducted on brain specimens $(n=206)$ from schizophrenia, bipolar disorder, and major depressive disorder patients, Narp transcript expression was measured at the level of the dorsolateral prefrontal cortex. A significant $25 \%$ reduction of Narp mRNA expression was detected in schizophrenia patients compared to normal controls (Kimoto et al., 2015). Moreover, as in the case of Npas4, the expression of Narp after antipsychotic administration has been explored only in one study to date. Indeed, the IEG has been demonstrated to be differentially regulated by haloperidol (1 mg/kg i.p.) and clozapine $(20 \mathrm{mg} / \mathrm{kg}$ i.p.) in cortical and subcortical rat brain regions Particularly, it has been shown that clozapine causes a specific decrease of Narp in the striatum (Robbins et al., 2008).

In summary, Npas4 and Narp share peculiar IEGs characteristics, the first one being expressed exclusively in neurons, and the second one being specifically secreted onto pyramidal cells. Both are deeply linked to glutamatergic and GABAergic functions. All the above-mentioned features make these early genes potential great players both in schizophrenia pathophysiology and in antipsychotic mechanisms of action at the intracellular level. Therefore, further studies are required in order to better clarify their putative specific roles in the disease development and treatment strategies.

\section{CONCLUSIONS}

\section{IEGs May Set the Scenario for Acute and Long-Term Changes Induced by Antipsychotics}

Antipsychotic agents are the mainstay of treatment in schizophrenia and in other psychotic disorders. However, despite half a century of research, their ultimate molecular actions and the neurobiological mechanisms beyond D2R occupancy are still elusive. In vivo human studies have shown that volumetric and functional changes may occur after chronic antipsychotic treatment and that some changes may be detected even after acute antipsychotic administration. Notably, schizophrenia has been considered a disease of synaptic plasticity and of dendritic spines (Penzes et al., 2011), and it is conceivable that antipsychotics exert their action by triggering a complex set of structural and functional modifications, also at the level of dendritic spines (De Bartolomeis et al., 2014). 
Tracking down the initial wave of molecular changes from multiple receptor interactions to dendritic spines modifications is a challenging task. In this context, IEGs may represent ideal candidates to explore how antipsychotics may set the scenario for acute and chronic re-arrangements of genes expression at the synapse.

This essential role of IEGs may be justified by multiple reasons:

1) IEGs control the early molecular processes of rapid synaptic plasticity induced by antipsychotics, which do not always require de novo protein synthesis.

2) IEGs are pleiotropic molecules that, beyond the common feature of being activated rapidly by diversified stimuli, are characterized by differential and specific functions spanning from transcription modulation (i.e., $c-f o s$ ), to neurotrophic action (i.e., $B D N F$ ), to regulation of scaffolding proteins at the PSD (i.e., Homer1a), all of which have been demonstrated to be induced by antipsychotics.

3) IEGs are strongly involved in complex higher functions affected by antipsychotics in key brain regions implicated in memory and learning (i.e., prefrontal cortex), as well as in reward and volition (i.e., limbic circuits), all of which have been demonstrated to be altered in schizophrenia (Leber et al., 2017).

4) IEGs expression may vary in response to antipsychotics, with a differential level of expression related to the receptor-binding profile (i.e., antipsychotics with prevalent dopaminergic activity vs. antipsychotics with more complex receptor profiles), to the dose, and to the duration of the treatment.

5) Different antipsychotic compounds have been demonstrated to induce specific patterns of IEGs expression in peculiar brain areas implicated in schizophrenia pathophysiology (Matosin et al., 2016).

\section{Future Steps toward a Further Clarification of IEGs Modulation by Antipsychotics}

Despite the lot of findings that highlight the complex modulation of IEGs by antipsychotics, the road for taking full advantage of this class of molecules in better understanding antipsychotics mechanisms of action is still long-lasting.

Here are listed few points that may make the issue progress:

1) It would be relevant to develop a research strategy to track down IEGs as putative blood biomarkers for antipsychotics activity under a diagnostic and therapeutic ("theranostic") approach. A recent preclinical investigation has tried to apply this strategy to antidepressant therapy starting from IEGs comparative analysis in brain regions and blood (Waller et al., 2017).

2) IEGs monitoring after acute or continuous antipsychotic treatments should be carried out in in vivo models, in order to better understand the role of this class of molecules in the mechanisms of action of antipsychotics. For example, multiphoton imaging of IEGs signals in cortical circuits has already been successfully used to get information on Egr1 expression after the exposure to a novel context (Xie et al., 2014).

3) The correlation among IEGs induction, antipsychotics, and epigenetic modulation is an attractive new scenario worth to be explored, which is based on the demonstrated modulation of the methylome by antipsychotics, on the recent findings on epigenetic control of IEGs in brain, and on the relevance of the contextual epigenetic-based mechanisms regulating brain higher functions that are involved in psychosis pathophysiology (Saunderson et al., 2016; Srivas and Thakur, 2016).

4) Under a translational perspective, more pharmacogenomic studies and brain post-mortem imaging investigations evaluating antipsychotics-dependent IEGs induction are needed to address in humans the findings that have already been described in animal models.

5) Finally, and again from a translational perspective, it will be important to start considering the "druggable" potential of some IEGs such as Homer1a, in order to search for new putative therapeutic strategies that can reach the core of the synapse and eventually correct the alterations linked to aberrant synaptic plasticity (Dev, 2004; Menard et al., 2015).

In sum, IEGs modulation by antipsychotics may provide a key tool to better understand the brain topography of antipsychotic action, the multiple pathways involved in the acute effects of these therapeutics beyond receptor interactions, as well as the molecular background for long-term changes of synaptic architecture promoted by chronic antipsychotic exposure.

\section{AUTHOR CONTRIBUTIONS}

AdB conceived the rationale and the structure of the review, wrote the manuscript and revised the literature search; EB analyzed the literature, contributed to write some sections of the second draft and to revise the final draft; FI, CT, GL, and FM revised and made contribution on the final draft; RR made the initial literature research and contribute to write partially the first draft of the manuscript; CT made the literature search, contributed to write the different drafts of the article.

\section{FUNDING}

This work was made possible partially thanks to an intramural grant of the Department of Neuroscience, Reproductive Sciences and Odontostomatology to the Section of Psychiatry and to the Laboratory of Molecular and Translational Psychiatry.

\section{ACKNOWLEDGMENTS}

We would like to acknowledge the critical discussion on the content of the review of all the members of the Laboratory of Molecular and Translational Psychiatry at University Medical School of Naples "Federico II." 


\section{REFERENCES}

Ahmed, M. R., Gurevich, V. V., Dalby, K. N., Benovic, J. L., and Gurevich, E. V. (2008). Haloperidol and clozapine differentially affect the expression of arrestins, receptor kinases, and extracellular signal-regulated kinase activation. J. Pharmacol. Exp. Ther. 325, 276-283. doi: 10.1124/jpet.107.131987

Aicardi, G., Argilli, E., Cappello, S., Santi, S., Riccio, M., Thoenen, H., et al. (2004). Induction of long-term potentiation and depression is reflected by corresponding changes in secretion of endogenous brainderived neurotrophic factor. Proc. Natl. Acad. Sci. U.S.A. 101, 15788-15792. doi: 10.1073/pnas.0406960101

Aid, T., Kazantseva, A., Piirsoo, M., Palm, K., and Timmusk, T. (2007). Mouse and rat BDNF gene structure and expression revisited. J. Neurosci. Res. 85, 525-535. doi: 10.1002/jnr.21139

Alme, M. N., Wibrand, K., Dagestad, G., and Bramham, C. R. (2007). Chronic fluoxetine treatment induces brain region-specific upregulation of genes associated with BDNF-induced long-term potentiation. Neural Plast. 2007:26496. doi: 10.1155/2007/26496

Alonso, M., Medina, J. H., and Pozzo-Miller, L. (2004). ERK1/2 activation is necessary for BDNF to increase dendritic spine density in hippocampal CA1 pyramidal neurons. Learn. Mem. 11, 172-178. doi: 10.1101/lm.67804

Ambesi-Impiombato, A., Panariello, F., Dell'aversano, C., Tomasetti, C., Muscettola, G., and De Bartolomeis, A. (2007). Differential expression of Homer 1 gene by acute and chronic administration of antipsychotics and dopamine transporter inhibitors in the rat forebrain. Synapse 61, 429-439. doi: 10.1002/syn.20385

Amemori, K., Gibb, L. G., and Graybiel, A. M. (2011). Shifting responsibly: the importance of striatal modularity to reinforcement learning in uncertain environments. Front. Hum. Neurosci. 5:47. doi: 10.3389/fnhum.2011.00047

Amin, E., Pearce, J. M., Brown, M. W., and Aggleton, J. P. (2006). Novel temporal configurations of stimuli produce discrete changes in immediateearly gene expression in the rat hippocampus. Eur. J. Neurosci. 24, 2611-2621. doi: 10.1111/j.1460-9568.2006.05131.x

Ancin, I., Cabranes, J. A., Vazquez-Alvarez, B., Santos, J. L., Sanchez-Morla, E., Alaerts, M., et al. (2013). NR4A2: effects of an "orphan" receptor on sustained attention in a schizophrenic population. Schizophr. Bull. 39, 555-563. doi: $10.1093 /$ schbul/sbr176

Angelucci, F., Mathe, A. A., and Aloe, L. (2000). Brain-derived neurotrophic factor and tyrosine kinase receptor $\operatorname{TrkB}$ in rat brain are significantly altered after haloperidol and risperidone administration. J. Neurosci. Res. 60, 783-794. doi: 10.1002/1097-4547(20000615)60:6\&lt;783::AID-JNR11\&gt;3.0.CO;2-M

Atkins, J. B., Chlan-Fourney, J., Nye, H. E., Hiroi, N., Carlezon, W. A. Jr., and Nestler, E. J. (1999). Region-specific induction of deltaFosB by repeated administration of typical versus atypical antipsychotic drugs. Synapse 33, 118-128. doi: 10.1002/(SICI)1098-2396(199908)33:2<118::AID-SYN2>3.0.CO;2-L

Backman, C., Perlmann, T., Wallen, A., Hoffer, B. J., and Morales, M. (1999). A selective group of dopaminergic neurons express Nurr1 in the adult mouse brain. Brain Res. 851, 125-132. doi: 10.1016/S0006-8993(99)02149-6

Bai, O., Chlan-Fourney, J., Bowen, R., Keegan, D., and Li, X. M. (2003). Expression of brain-derived neurotrophic factor mRNA in rat hippocampus after treatment with antipsychotic drugs. J. Neurosci. Res. 71, 127-131. doi: 10.1002/jnr.10440

Balleine, B. W., and O'doherty, J. P. (2010). Human and rodent homologies in action control: corticostriatal determinants of goal-directed and habitual action. Neuropsychopharmacology 35, 48-69. doi: 10.1038/npp.2009.131

Baquet, Z. C., Bickford, P. C., and Jones, K. R. (2005). Brain-derived neurotrophic factor is required for the establishment of the proper number of dopaminergic neurons in the substantia nigra pars compacta. J. Neurosci. 25, 6251-6259. doi: 10.1523/JNEUROSCI.4601-04.2005

Barnes, P., Kirtley, A., and Thomas, K. L. (2012). Quantitatively and qualitatively different cellular processes are engaged in CA1 during the consolidation and reconsolidation of contextual fear memory. Hippocampus 22, 149-171. doi: 10.1002/hipo.20879

Beaudry, G., Langlois, M. C., Weppe, I., Rouillard, C., and Levesque, D. (2000). Contrasting patterns and cellular specificity of transcriptional regulation of the nuclear receptor nerve growth factor-inducible B by haloperidol and clozapine in the rat forebrain. J. Neurochem. 75, 1694-1702. doi: 10.1046/j.1471-4159.2000.0751694.x
Beckervordersandforth, R., Zhang, C. L., and Lie, D. C. (2015). Transcriptionfactor-dependent control of adult hippocampal neurogenesis. Cold Spring Harb. Perspect. Biol. 7:a018879. doi: 10.1101/cshperspect.a018879

Beckmann, A. M., and Wilce, P. A. (1997). Egr transcription factors in the nervous system. Neurochem. Int. 31, 477-510; discussion: 517-6. doi: 10.1016/S0197-0186(96)00136-2

Benedetti, F., Poletti, S., Locatelli, C., Mazza, E., Lorenzi, C., Vitali, A., et al. (2018). A Homer 1 gene variant influences brain structure and function, lithium effects on white matter, and antidepressant response in bipolar disorder: a multimodal genetic imaging study. Prog. Neuropsychopharmacol. Biol. Psychiatry 81, 88-95. doi: 10.1016/j.pnpbp.2017.10.011

Benito, E., and Barco, A. (2015). The neuronal activity-driven transcriptome. $\mathrm{Mol}$. Neurobiol. 51, 1071-1088. doi: 10.1007/s12035-014-8772-z

Bepari, A. K., Sano, H., Tamamaki, N., Nambu, A., Tanaka, K. F., and Takebayashi, H. (2012). Identification of optogenetically activated striatal medium spiny neurons by Npas4 expression. PLoS ONE 7:e52783. doi: 10.1371/journal.pone.0052783

Bigio, B., Mathe, A. A., Sousa, V. C., Zelli, D., Svenningsson, P., McEwen, B. S., et al. (2016). Epigenetics and energetics in ventral hippocampus mediate rapid antidepressant action: implications for treatment resistance. Proc. Natl. Acad. Sci. U.S.A. 113, 7906-7911. doi: 10.1073/pnas.1603111113

Bloomer, W. A., Vandongen, H. M., and Vandongen, A. M. (2008). Arc/Arg3.1 translation is controlled by convergent N-methyl-D-aspartate and Gscoupled receptor signaling pathways. J. Biol. Chem. 283, 582-592. doi: 10.1074/jbc.M702451200

Bottai, D., Guzowski, J. F., Schwarz, M. K., Kang, S. H., Xiao, B., Lanahan, A., et al. (2002). Synaptic activity-induced conversion of intronic to exonic sequence in Homer 1 immediate early gene expression. J. Neurosci. 22, 167-175.

Bourhis, E., Maheux, J., Rouillard, C., and Levesque, D. (2008). Extracellular signalregulated kinases (ERK) and protein kinase $\mathrm{C}(\mathrm{PKC})$ activities are involved in the modulation of Nur77 and Nor-1 expression by dopaminergic drugs. J. Neurochem. 106, 875-888. doi: 10.1111/j.1471-4159.2008.05455.x

Boyajyan, A., Zakharyan, R., Atshemyan, S., Chavushyan, A., and Mkrtchyan, G. (2015). Schizophrenia-associated risk and protective variants of c-Fos encoding gene. Recent Adv. DNA Gene Seq. 9, 51-57. doi: 10.2174/2352092209666150223113334

Bramham, C. R., Alme, M. N., Bittins, M., Kuipers, S. D., Nair, R. R., Pai, B., et al. (2010). The Arc of synaptic memory. Exp. Brain Res. 200, 125-140. doi: 10.1007/s00221-009-1959-2

Bubser, M., and Deutch, A. Y. (2002). Differential effects of typical and atypical antipsychotic drugs on striosome and matrix compartments of the striatum. Eur. J. Neurosci. 15, 713-720. doi: 10.1046/j.1460-9568.2002.01903.x

Buervenich, S., Carmine, A., Arvidsson, M., Xiang, F., Zhang, Z., Sydow, O., et al. (2000). NURR1 mutations in cases of schizophrenia and manic-depressive disorder. Am. J. Med. Genet. 96, 808-813. doi: 10.1002/1096-8628(20001204)96:6\&lt;808::AID-AJMG23\&gt;3.0.CO;2-E

Buonaguro, E. F., Iasevoli, F., Marmo, F., Eramo, A., Latte, G., Avagliano, C., et al. (2017a). Re-arrangements of gene transcripts at glutamatergic synapses after prolonged treatments with antipsychotics: a putative link with synaptic remodeling. Prog. Neuropsychopharmacol. Biol. Psychiatry 76, 29-41. doi: 10.1016/j.pnpbp.2017.02.012

Buonaguro, E. F., Tomasetti, C., Chiodini, P., Marmo, F., Latte, G., Rossi, R., et al. (2017b). Postsynaptic density protein transcripts are differentially modulated by minocycline alone or in add-on to haloperidol: implications for treatment resistant schizophrenia. J. Psychopharmacol. 31, 406-417. doi: $10.1177 / 0269881116658987$.

Calabrese, F., Molteni, R., Gabriel, C., Mocaer, E., Racagni, G., and Riva, M. A. (2011). Modulation of neuroplastic molecules in selected brain regions after chronic administration of the novel antidepressant agomelatine. Psychopharmacology 215, 267-275. doi: 10.1007/s00213-010-2129-8

Campos-Melo, D., Galleguillos, D., Sanchez, N., Gysling, K., and Andres, M. E. (2013). Nur transcription factors in stress and addiction. Front. Mol. Neurosci. 6:44. doi: 10.3389/fnmol.2013.00044

Cannon, T. D., Chung, Y., He, G., Sun, D., Jacobson, A., Van Erp, T. G., et al. (2015). Progressive reduction in cortical thickness as psychosis develops: a multisite longitudinal neuroimaging study of youth at elevated clinical risk. Biol. Psychiatry 77, 147-157. doi: 10.1016/j.biopsych.2014.05.023

Castner, S. A., Goldman-Rakic, P. S., and Williams, G. V. (2004). Animal models of working memory: insights for targeting cognitive dysfunction in 
schizophrenia. Psychopharmacology 174, 111-125. doi: 10.1007/s00213-003$1710-9$

Castren, E., Da Penha Berzaghi, M., Lindholm, D., and Thoenen, H. (1993). Differential effects of MK-801 on brain-derived neurotrophic factor mRNA levels in different regions of the rat brain. Exp. Neurol. 122, 244-252. doi: 10.1006/exnr.1993.1124

Chang, M. C., Park, J. M., Pelkey, K. A., Grabenstatter, H. L., Xu, D., Linden, D. J., et al. (2010). Narp regulates homeostatic scaling of excitatory synapses on parvalbumin-expressing interneurons. Nat. Neurosci. 13, 1090-1097. doi: $10.1038 / \mathrm{nn} .2621$

Chen, Q. Y., Chen, Q., Feng, G. Y., Wan, C. L., Lindpaintner, K., Wang, L. J., et al. (2006). Association between the brain-derived neurotrophic factor (BDNF) gene and schizophrenia in the Chinese population. Neurosci. Lett. 397, 285-290. doi: 10.1016/j.neulet.2005.12.033

Chen, W. G., West, A. E., Tao, X., Corfas, G., Szentirmay, M. N., Sawadogo, M., et al. (2003). Upstream stimulatory factors are mediators of $\mathrm{Ca} 2+$-responsive transcription in neurons. J. Neurosci. 23, 2572-2581.

Chen, Z. Y., Patel, P. D., Sant, G., Meng, C. X., Teng, K. K., Hempstead, B. L., et al. (2004). Variant brain-derived neurotrophic factor (BDNF) (Met66) alters the intracellular trafficking and activity-dependent secretion of wild-type BDNF in neurosecretory cells and cortical neurons. J. Neurosci. 24, 4401-4411. doi: 10.1523/JNEUROSCI.0348-04.2004

Cheval, H., Chagneau, C., Levasseur, G., Veyrac, A., Faucon-Biguet, N., Laroche, S., et al. (2012). Distinctive features of Egr transcription factor regulation and DNA binding activity in CAl of the hippocampus in synaptic plasticity and consolidation and reconsolidation of fear memory. Hippocampus 22, 631-642. doi: 10.1002/hipo. 20926

Chlan-Fourney, J., Ashe, P., Nylen, K., Juorio, A. V., and Li, X. M. (2002). Differential regulation of hippocampal BDNF mRNA by typical and atypical antipsychotic administration. Brain Res. 954, 11-20. doi: 10.1016/S0006-8993(02)03215-8

Chowdhury, S., Shepherd, J. D., Okuno, H., Lyford, G., Petralia, R. S., Plath, N., et al. (2006). Arc/Arg3.1 interacts with the endocytic machinery to regulate AMPA receptor trafficking. Neuron 52, 445-459. doi: 10.1016/j.neuron.2006.08.033

Cochran, S. M., McKerchar, C. E., Morris, B. J., and Pratt, J. A. (2002). Induction of differential patterns of local cerebral glucose metabolism and immediate-early genes by acute clozapine and haloperidol. Neuropharmacology 43, 394-407. doi: 10.1016/S0028-3908(02)00091-6

Collins, C. M., Wood, M. D., and Elliott, J. M. (2014). Chronic administration of haloperidol and clozapine induces differential effects on the expression of Arc and c-Fos in rat brain. J. Psychopharmacol. 28, 947-954. doi: $10.1177 / 0269881114536788$

Coutellier, L., Beraki, S., Ardestani, P. M., Saw, N. L., and Shamloo, M. (2012). Npas4: a neuronal transcription factor with a key role in social and cognitive functions relevant to developmental disorders. PLOS ONE 7:e46604. doi: 10.1371/journal.pone.0046604

Dahl, J. P., Kampman, K. M., Oslin, D. W., Weller, A. E., Lohoff, F. W., Ferraro, T. N., et al. (2005). Association of a polymorphism in the Homerl gene with cocaine dependence in an African American population. Psychiatr. Genet. 15, 277-283. doi: 10.1097/00041444-200512000-00010

Daunais, J. B., and McGinty, J. F. (1996). The effects of D1 or D2 dopamine receptor blockade on zif/268 and preprodynorphin gene expression in rat forebrain following a short-term cocaine binge. Brain Res. Mol. Brain Res. 35, 237-248. doi: 10.1016/0169-328X(95)00226-I

Davis, S., Bozon, B., and Laroche, S. (2003). How necessary is the activation of the immediate early gene zif268 in synaptic plasticity and learning? Behav. Brain Res. 142, 17-30. doi: 10.1016/S0166-4328(02)00421-7

De Bartolomeis, A., Avvisati, L., Iasevoli, F., and Tomasetti, C. (2013a). Intracellular pathways of antipsychotic combined therapies: implication for psychiatric disorders treatment. Eur. J. Pharmacol. 718, 502-523. doi: 10.1016/j.ejphar.2013.06.034

De Bartolomeis, A., and Iasevoli, F. (2003). The Homer family and the signal transduction system at glutamatergic postsynaptic density: potential role in behavior and pharmacotherapy. Psychopharmacol. Bull. 37, 51-83.

De Bartolomeis, A., Iasevoli, F., Marmo, F., Buonaguro, E. F., Eramo, A., Rossi, R., et al. (2015a). Progressive recruitment of cortical and striatal regions by inducible postsynaptic density transcripts after increasing doses of antipsychotics with different receptor profiles: insights for psychosis treatment. Eur. Neuropsychopharmacol. 25, 566-582. doi: 10.1016/j.euroneuro.2015.01.003

De Bartolomeis, A., Latte, G., Tomasetti, C., and Iasevoli, F. (2014). Glutamatergic postsynaptic density protein dysfunctions in synaptic plasticity and dendritic spines morphology: relevance to schizophrenia and other behavioral disorders pathophysiology, and implications for novel therapeutic approaches. Mol. Neurobiol. 49, 484-511. doi: 10.1007/s12035-013-8534-3

De Bartolomeis, A., Marmo, F., Buonaguro, E. F., Latte, G., Tomasetti, C., and Iasevoli, F. (2016). Switching antipsychotics: imaging the differential effect on the topography of postsynaptic density transcripts in antipsychotic-naive vs. antipsychotic-exposed rats. Prog. Neuropsychopharmacol. Biol. Psychiatry 70, 24-38. doi: 10.1016/j.pnpbp.2016.04.015

De Bartolomeis, A., Marmo, F., Buonaguro, E. F., Rossi, R., Tomasetti, C., and Iasevoli, F. (2013b). Imaging brain gene expression profiles by antipsychotics: region-specific action of amisulpride on postsynaptic density transcripts compared to haloperidol. Eur. Neuropsychopharmacol. 23, 1516-1529. doi: 10.1016/j.euroneuro.2012.11.014

De Bartolomeis, A., Tomasetti, C., Cicale, M., Yuan, P. X., and Manji, H. K. (2012). Chronic treatment with lithium or valproate modulates the expression of Homer1b/c and its related genes Shank and Inositol 1,4,5-trisphosphate receptor. Eur. Neuropsychopharmacol. 22, 527-535. doi: 10.1016/j.euroneuro.2011.11.006

De Bartolomeis, A., Tomasetti, C., and Iasevoli, F. (2015b). Update on the mechanism of action of aripiprazole: translational insights into antipsychotic strategies beyond dopamine receptor antagonism. CNS Drugs 29, 773-799. doi: $10.1007 / \mathrm{s} 40263-015-0278-3$

De Foubert, G., Carney, S. L., Robinson, C. S., Destexhe, E. J., Tomlinson, R., Hicks, C. A., et al. (2004). Fluoxetine-induced change in rat brain expression of brain-derived neurotrophic factor varies depending on length of treatment. Neuroscience 128, 597-604. doi: 10.1016/j.neuroscience.2004.06.054

Dell'aversano, C., Tomasetti, C., Iasevoli, F., and De Bartolomeis, A. (2009). Antipsychotic and antidepressant co-treatment: effects on transcripts of inducible postsynaptic density genes possibly implicated in behavioural disorders. Brain Res. Bull. 79, 123-129. doi: 10.1016/j.brainresbull.2009.01.006

De Luca, V., Annesi, G., De Marco, E. V., De Bartolomeis, A., Nicoletti, G., Pugliese, P., et al. (2009). HOMER1 promoter analysis in Parkinson's disease: association study with psychotic symptoms. Neuropsychobiology 59, 239-245. doi: 10.1159/000230689

Deutch, A. Y., Moghaddam, B., Innis, R. B., Krystal, J. H., Aghajanian, G. K., Bunney, B. S., et al. (1991). Mechanisms of action of atypical antipsychotic drugs. Implications for novel therapeutic strategies for schizophrenia. Schizophr. Res. 4, 121-156. doi: 10.1016/0920-9964(91)90030-U

Deutch, A. Y., Ongur, D., and Duman, R. S. (1995). Antipsychotic drugs induce Fos protein in the thalamic paraventricular nucleus: a novel locus of antipsychotic drug action. Neuroscience 66, 337-346. doi: 10.1016/0306-4522(94)00571-L

Dev, K. K. (2004). Making protein interactions druggable: targeting PDZ domains. Nat. Rev. Drug Discov. 3, 1047-1056. doi: 10.1038/nrd1578

Dietz, A., Buschermohle, M., Aarnisalo, A. A., Vanhanen, A., Hyyrynen, T., Aaltonen, O., et al. (2014). The development and evaluation of the finnish matrix sentence test for speech intelligibility assessment. Acta Otolaryngol. 134, 728-737. doi: 10.3109/00016489.2014.898185

Doyle, S., Pyndiah, S., De Gois, S., and Erickson, J. D. (2010). Excitationtranscription coupling via calcium/calmodulin-dependent protein kinase/ERK1/2 signaling mediates the coordinate induction of VGLUT2 and Narp triggered by a prolonged increase in glutamatergic synaptic activity. J. Biol. Chem. 285, 14366-14376. doi: 10.1074/jbc.M109.080069

Dragunow, M. (1990). Presence and induction of Fos B-like immunoreactivity in neural, but not non-neural, cells in adult rat brain. Brain Res. 533, 324-328. doi: 10.1016/0006-8993(90)91357-M

Durchdewald, M., Angel, P., and Hess, J. (2009). The transcription factor Fos: a Janus-type regulator in health and disease. Histol. Histopathol. 24, 1451-1461. doi: 10.14670/HH-24.1451

Eastwood, S. L. (2004). The synaptic pathology of schizophrenia: is aberrant neurodevelopment and plasticity to blame? Int. Rev. Neurobiol. 59, 47-72. doi: 10.1016/S0074-7742(04)59003-7

Eells, J. B., Wilcots, J., Sisk, S., and Guo-Ross, S. X. (2012). NR4A gene expression is dynamically regulated in the ventral tegmental area dopamine neurons and 
is related to expression of dopamine neurotransmission genes. J. Mol. Neurosci. 46, 545-553. doi: 10.1007/s12031-011-9642-z

Ehrlich, D. E., and Josselyn, S. A. (2016). Plasticity-related genes in brain development and amygdala-dependent learning. Genes Brain Behav. 15, 125-143. doi: 10.1111/gbb.12255

Emsley, R., Asmal, L., Du Plessis, S., Chiliza, B., Kidd, M., Carr, J., et al. (2015). Dorsal striatal volumes in never-treated patients with first-episode schizophrenia before and during acute treatment. Schizophr. Res. 169, 89-94. doi: 10.1016/j.schres.2015.09.014

Emsley, R., Asmal, L., Du Plessis, S., Chiliza, B., Phahladira, L., and Kilian, S. (2017). Brain volume changes over the first year of treatment in schizophrenia: relationships to antipsychotic treatment. Psychol. Med. 47, 2187-2196. doi: 10.1017/S0033291717000642

Engmann, O., Giralt, A., and Girault, J. A. (2016). Acute drug-induced spine changes in the nucleus accumbens are dependent on beta-adducin. Neuropharmacology 110, 333-342. doi: 10.1016/j.neuropharm.2016.07.035

Ethier, I., Beaudry, G., St-Hilaire, M., Milbrandt, J., Rouillard, C., and Levesque, D. (2004). The transcription factor NGFI-B (Nur77) and retinoids play a critical role in acute neuroleptic-induced extrapyramidal effect and striatal neuropeptide gene expression. Neuropsychopharmacology 29, 335-346. doi: 10.1038/sj.npp.1300318

Fernandes, A. R., and Chari, D. M. (2016). Part II: functional delivery of a neurotherapeutic gene to neural stem cells using minicircle DNA and nanoparticles: translational advantages for regenerative neurology. J. Control. Release 238, 300-310. doi: 10.1016/j.jconrel.2016.06.039

Fromer, M., Pocklington, A. J., Kavanagh, D. H., Williams, H. J., Dwyer, S., Gormley, P., et al. (2014). De novo mutations in schizophrenia implicate synaptic networks. Nature 506, 179-184. doi: 10.1038/nature12929

Fumagalli, F., Calabrese, F., Luoni, A., Bolis, F., Racagni, G., and Riva, M. A. (2012). Modulation of BDNF expression by repeated treatment with the novel antipsychotic lurasidone under basal condition and in response to acute stress. Int. J. Neuropsychopharmacol. 15, 235-246. doi: 10.1017/S1461145711000150

Fumagalli, F., Frasca, A., Racagni, G., and Riva, M. A. (2009). Antipsychotic drugs modulate Arc expression in the rat brain. Eur. Neuropsychopharmacol. 19, 109-115. doi: 10.1016/j.euroneuro.2008.09.001

Fumagalli, F., Molteni, R., Roceri, M., Bedogni, F., Santero, R., Fossati, C., et al. (2003). Effect of antipsychotic drugs on brain-derived neurotrophic factor expression under reduced N-methyl-D-aspartate receptor activity. J. Neurosci. Res. 72, 622-628. doi: 10.1002/jnr.10609

Gangarossa, G., Di Benedetto, M., O'sullivan, G. J., Dunleavy, M., Alcacer, C., Bonito-Oliva, A., et al. (2011). Convulsant doses of a dopamine D1 receptor agonist result in Erk-dependent increases in Zif268 and Arc/Arg3.1 expression in mouse dentate gyrus. PLoS ONE 6:e19415. doi: 10.1371/journal.pone.0019415.

Gao, C., Tronson, N. C., and Radulovic, J. (2013). Modulation of behavior by scaffolding proteins of the post-synaptic density. Neurobiol. Learn. Mem. 105, 3-12. doi: 10.1016/j.nlm.2013.04.014

Gao, M., Sossa, K., Song, L., Errington, L., Cummings, L., Hwang, H., et al. (2010). A specific requirement of Arc/Arg3.1 for visual experience-induced homeostatic synaptic plasticity in mouse primary visual cortex. J. Neurosci. 30, 7168-7178. doi: 10.1523/JNEUROSCI.1067-10.2010

Gartner, A., Polnau, D. G., Staiger, V., Sciarretta, C., Minichiello, L., Thoenen, H., et al. (2006). Hippocampal long-term potentiation is supported by presynaptic and postsynaptic tyrosine receptor kinase B-mediated phospholipase Cgamma signaling. J. Neurosci. 26, 3496-3504. doi: 10.1523/JNEUROSCI.3792-05.2006

Geddes, J. R., and Miklowitz, D. J. (2013). Treatment of bipolar disorder. Lancet 381, 1672-1682. doi: 10.1016/S0140-6736(13)60857-0

Gentzel, R. C., Toolan, D., Roberts, R., Koser, A. J., Kandebo, M., Hershey, J., et al. (2015). The PDE10A inhibitor MP-10 and haloperidol produce distinct gene expression profiles in the striatum and influence cataleptic behavior in rodents. Neuropharmacology 99, 256-263. doi: 10.1016/j.neuropharm.2015.05.024

Gerlach, R., Beck, M., Zeitschel, U., and Seifert, V. (2002). MK 801 attenuates c-Fos and c-Jun expression after in vitro ischemia in rat neuronal cell cultures but not in PC 12 cells. Neurol. Res. 24, 725-729. doi: 10.1179/016164102101200654

Ghasemzadeh, M. B., Windham, L. K., Lake, R. W., Acker, C. J., and Kalivas, P. W. (2009). Cocaine activates Homerl immediate early gene transcription in the mesocorticolimbic circuit: differential regulation by dopamine and glutamate signaling. Synapse 63, 42-53. doi: 10.1002/syn.20577
Ghosh, A., Ginty, D. D., Bading, H., and Greenberg, M. E. (1994). Calcium regulation of gene expression in neuronal cells. J. Neurobiol. 25, 294-303. doi: 10.1002/neu.480250309

Gill, K. M., Bernstein, I. L., and Mizumori, S. J. (2007). Immediate early gene activation in hippocampus and dorsal striatum: effects of explicit place and response training. Neurobiol. Learn. Mem. 87, 583-596. doi: 10.1016/j.nlm.2006.12.011

Ginovart, N., and Kapur, S. (2012). Role of dopamine D(2) receptors for antipsychotic activity. Handb. Exp. Pharmacol. 212, 27-52. doi: 10.1007/978-3-642-25761-2_2

Gonzalez-Maeso, J., Yuen, T., Ebersole, B. J., Wurmbach, E., Lira, A., Zhou, M., et al. (2003). Transcriptome fingerprints distinguish hallucinogenic and nonhallucinogenic 5-hydroxytryptamine $2 \mathrm{~A}$ receptor agonist effects in mouse somatosensory cortex. J. Neurosci. 23, 8836-8843.

Gonzalez-Pinto, A., Mosquera, F., Palomino, A., Alberich, S., Gutierrez, A., Haidar, K., et al. (2010). Increase in brain-derived neurotrophic factor in first episode psychotic patients after treatment with atypical antipsychotics. Int. Clin. Psychopharmacol. 25, 241-245. doi: 10.1097/YIC.0b013e328338bc5a

Grant, S. G. (2012). Synaptopathies: diseases of the synaptome. Curr. Opin. Neurobiol. 22, 522-529. doi: 10.1016/j.conb.2012.02.002

Green, M. F. (1996). What are the functional consequences of neurocognitive deficits in schizophrenia? Am. J. Psychiatry 153, 321-330.

Green, M. J., Matheson, S. L., Shepherd, A., Weickert, C. S., and Carr, V. J. (2011). Brain-derived neurotrophic factor levels in schizophrenia: a systematic review with meta-analysis. Mol. Psychiatry 16, 960-972. doi: 10.1038/mp.2010.88

Grillo, R. W., Ottoni, G. L., Leke, R., Souza, D. O., Portela, L. V., and Lara, D. R. (2007). Reduced serum BDNF levels in schizophrenic patients on clozapine or typical antipsychotics. J. Psychiatr. Res. 41, 31-35. doi: 10.1016/j.jpsychires.2006.01.005

Guillin, O., Diaz, J., Carroll, P., Griffon, N., Schwartz, J. C., and Sokoloff, P. (2001). BDNF controls dopamine D3 receptor expression and triggers behavioural sensitization. Nature 411, 86-89. doi: 10.1038/35075076

Hayashi, Y., Okamoto, K., Bosch, M., and Futai, K. (2012). Roles of neuronal activity-induced gene products in Hebbian and homeostatic synaptic plasticity, tagging, and capture. Adv. Exp. Med. Biol. 970, 335-354. doi: 10.1007/978-3-7091-0932-8_15

Hernandez, P. J., Schiltz, C. A., and Kelley, A. E. (2006). Dynamic shifts in corticostriatal expression patterns of the immediate early genes Homer 1a and Zif268 during early and late phases of instrumental training. Learn. Mem. 13, 599-608. doi: 10.1101/lm.335006

Herrera, R., Agarwal, S., Walton, K., Satterberg, B., Distel, R. J., Goodman, R., et al. (1990). A direct role for c-fos in AP-1-dependent gene transcription. Cell Growth Differ. 1, 483-490.

Hiroi, N., and Graybiel, A. M. (1996). Atypical and typical neuroleptic treatments induce distinct programs of transcription factor expression in the striatum. J. Comp. Neurol. 374, 70-83. doi: 10.1002/(SICI)1096-9861(19961007)374:1<70::AID-CNE5>3.0.CO;2-K

Ho, B. C., Andreasen, N. C., Ziebell, S., Pierson, R., and Magnotta, V. (2011). Long-term antipsychotic treatment and brain volumes: a longitudinal study of first-episode schizophrenia. Arch. Gen. Psychiatry 68, 128-137. doi: 10.1001/archgenpsychiatry.2010.199

Hong, C. J., Yu, Y. W., Lin, C. H., and Tsai, S. J. (2003). An association study of a brain-derived neurotrophic factor Val66Met polymorphism and clozapine response of schizophrenic patients. Neurosci. Lett. 349, 206-208. doi: 10.1016/S0304-3940(03)00828-0

Hu, J. H., Park, J. M., Park, S., Xiao, B., Dehoff, M. H., Kim, S., et al. (2010). Homeostatic scaling requires group I mGluR activation mediated by Homerla. Neuron 68, 1128-1142. doi: 10.1016/j.neuron.2010.11.008

Huentelman, M. J., Muppana, L., Corneveaux, J. J., Dinu, V., Pruzin, J. J., Reiman, R., et al. (2015). Association of SNPs in EGR3 and ARC with Schizophrenia supports a biological pathway for schizophrenia risk. PLoS ONE 10:e0135076. doi: 10.1371/journal.pone.0135076

Hughes, P., and Dragunow, M. (1995). Induction of immediate-early genes and the control of neurotransmitter-regulated gene expression within the nervous system. Pharmacol. Rev. 47, 133-178.

Iasevoli, F., Ambesi-Impiombato, A., Fiore, G., Panariello, F., Muscettola, G., and De Bartolomeis, A. (2011). Pattern of acute induction of Homerla gene is preserved after chronic treatment with first- and second-generation 
antipsychotics: effect of short-term drug discontinuation and comparison with Homerla-interacting genes. J. Psychopharmacol. 25, 875-887. doi: $10.1177 / 0269881109358199$

Iasevoli, F., Fiore, G., Cicale, M., Muscettola, G., and De Bartolomeis, A. (2010a). Haloperidol induces higher Homerla expression than risperidone, olanzapine and sulpiride in striatal sub-regions. Psychiatry Res. 177, 255-260. doi: 10.1016/j.psychres.2010.02.009

Iasevoli, F., Tomasetti, C., Ambesi-Impiombato, A., Muscettola, G., and De Bartolomeis, A. (2009). Dopamine receptor subtypes contribution to Homerla induction: insights into antipsychotic molecular action. Prog. Neuropsychopharmacol. Biol. Psychiatry 33, 813-821. doi: 10.1016/j.pnpbp.2009.02.009

Iasevoli, F., Tomasetti, C., and De Bartolomeis, A. (2013). Scaffolding proteins of the post-synaptic density contribute to synaptic plasticity by regulating receptor localization and distribution: relevance for neuropsychiatric diseases. Neurochem. Res. 38, 1-22. doi: 10.1007/s11064-012-0886-y

Iasevoli, F., Tomasetti, C., Marmo, F., Bravi, D., Arnt, J., and De Bartolomeis, A. (2010b). Divergent acute and chronic modulation of glutamatergic postsynaptic density genes expression by the antipsychotics haloperidol and sertindole. Psychopharmacology 212, 329-344. doi: 10.1007/s00213-010-1954-0

Iritani, S., Niizato, K., Nawa, H., Ikeda, K., and Emson, P. C. (2003). Immunohistochemical study of brain-derived neurotrophic factor and its receptor, TrkB, in the hippocampal formation of schizophrenic brains. Prog. Neuropsychopharmacol. Biol. Psychiatry 27, 801-807. doi: 10.1016/S0278-5846(03)00112-X

Jarskog, L. F. (2006). Apoptosis in schizophrenia: pathophysiologic and therapeutic considerations. Curr. Opin. Psychiatry 19, 307-312. doi: 10.1097/01.yco.0000218603.25346.8f

Jochum, W., Passegue, E., and Wagner, E. F. (2001). AP-1 in mouse development and tumorigenesis. Oncogene 20, 2401-2412. doi: 10.1038/sj.onc.1204389

Kagaya, S., Hashida, R., Ohkura, N., Tsukada, T., Sugita, Y., Terakawa, M., et al. (2005). NR4A orphan nuclear receptor family in peripheral blood eosinophils from patients with atopic dermatitis and apoptotic eosinophils in vitro. Int. Arch. Allergy Immunol. 137(Suppl. 1), 35-44. doi: 10.1159/000085430

Kandel, E. R. (2001). Psychotherapy and the single synapse: the impact of psychiatric thought on neurobiological research. (1979). J. Neuropsychiatry Clin. Neurosci. 13, 290-300; discussion: 289. doi: 10.1176/jnp.13.2.290

Kantrowitz, J. T. (2017). Managing negative symptoms of Schizophrenia: how far have we come? CNS Drugs. 31, 373-388. doi: 10.1007/s40263-017-0428-x.

Katagiri, Y., Hirata, Y., Milbrandt, J., and Guroff, G. (1997). Differential regulation of the transcriptional activity of the orphan nuclear receptor NGFI-B by membrane depolarization and nerve growth factor. J. Biol. Chem. 272, 31278-31284. doi: 10.1074/jbc.272.50.31278

Kim, H. W., Cheon, Y., Modi, H. R., Rapoport, S. I., and Rao, J. S. (2012). Effects of chronic clozapine administration on markers of arachidonic acid cascade and synaptic integrity in rat brain. Psychopharmacology 222, 663-674. doi: 10.1007/s00213-012-2671-7

Kimoto, S., Bazmi, H. H., and Lewis, D. A. (2014). Lower expression of glutamic acid decarboxylase 67 in the prefrontal cortex in schizophrenia: contribution of altered regulation by Zif268. Am. J. Psychiatry 171, 969-978. doi: 10.1176/appi.ajp.2014.14010004

Kimoto, S., Zaki, M. M., Bazmi, H. H., and Lewis, D. A. (2015). Altered markers of cortical gamma-aminobutyric acid neuronal activity in Schizophrenia: role of the NARP Gene. JAMA Psychiatry 72, 747-756. doi: 10.1001/jamapsychiatry.2015.0533

Kontkanen, O., Lakso, M., Wong, G., and Castren, E. (2002). Chronic antipsychotic drug treatment induces long-lasting expression of fos and jun family genes and activator protein 1 complex in the rat prefrontal cortex. Neuropsychopharmacology 27, 152-162. doi: 10.1016/S0893-133X(02)00289-0

Kovacs, K. J., Csejtei, M., and Laszlovszky, I. (2001). Double activity imaging reveals distinct cellular targets of haloperidol, clozapine and dopamine D(3) receptor selective RGH-1756. Neuropharmacology 40, 383-393. doi: 10.1016/S0028-3908(00)00163-5

Lam, B. Y., Zhang, W., Enticknap, N., Haggis, E., Cader, M. Z., and Chawla, S. (2009). Inverse regulation of plasticity-related immediate early genes by calcineurin in hippocampal neurons. J. Biol. Chem. 284, 12562-12571. doi: $10.1074 /$ jbc.M901121200
Lanahan, A., and Worley, P. (1998). Immediate-early genes and synaptic function. Neurobiol. Learn. Mem. 70, 37-43. doi: 10.1006/nlme.1998.3836

Langlois, M. C., Beaudry, G., Zekki, H., Rouillard, C., and Levesque, D. (2001). Impact of antipsychotic drug administration on the expression of nuclear receptors in the neocortex and striatum of the rat brain. Neuroscience 106, 117-128. doi: 10.1016/S0306-4522(01)00248-2

Lauterborn, J. C., Rivera, S., Stinis, C. T., Hayes, V. Y., Isackson, P. J., and Gall, C. M. (1996). Differential effects of protein synthesis inhibition on the activitydependent expression of BDNF transcripts: evidence for immediate-early gene responses from specific promoters. J. Neurosci. 16, 7428-7436.

Law, S. W., Conneely, O. M., Demayo, F. J., and O'malley, B. W. (1992). Identification of a new brain-specific transcription factor, NURR1. Mol. Endocrinol. 6, 2129-2135.

Leber, S. L., Llenos, I. C., Miller, C. L., Dulay, J. R., Haybaeck, J., and Weis, S. (2017). Homerla protein expression in schizophrenia, bipolar disorder, and major depression. J. Neural. Transm. 124, 1261-1273. doi: $10.1007 / \mathrm{s} 00702-017-1776-\mathrm{x}$

Lee, J. L. (2010). Memory reconsolidation mediates the updating of hippocampal memory content. Front. Behav. Neurosci. 4:168. doi: 10.3389/fnbeh.2010.00168

Lee, S. J., Wei, M., Zhang, C., Maxeiner, S., Pak, C., Calado Botelho, S., et al. (2017). Presynaptic neuronal pentraxin receptor organizes excitatory and inhibitory synapses. J. Neurosci. 37, 1062-1080. doi: 10.1523/JNEUROSCI.2768-16.2016

Li, Y., Ge, S., Li, N., Chen, L., Zhang, S., Wang, J., et al. (2016). NMDA and dopamine D1 receptors within NAc-shell regulate IEG proteins expression in reward circuit during cocaine memory reconsolidation. Neuroscience 315, 45-69. doi: 10.1016/j.neuroscience.2015.11.063

Linden, A. M., Vaisanen, J., Lakso, M., Nawa, H., Wong, G., and Castren, E. (2000). Expression of neurotrophins BDNF and NT-3, and their receptors in rat brain after administration of antipsychotic and psychotrophic agents. J. Mol. Neurosci. 14, 27-37. doi: 10.1385/JMN:14:1-2:027

Link, W., Konietzko, U., Kauselmann, G., Krug, M., Schwanke, B., Frey, U., et al. (1995). Somatodendritic expression of an immediate early gene is regulated by synaptic activity. Proc. Natl. Acad. Sci. U.S.A. 92, 5734-5738. doi: 10.1073/pnas.92.12.5734

Lipska, B. K., Khaing, Z. Z., Weickert, C. S., and Weinberger, D. R. (2001). BDNF mRNA expression in rat hippocampus and prefrontal cortex: effects of neonatal ventral hippocampal damage and antipsychotic drugs. Eur. J. Neurosci. 14, 135-144. doi: 10.1046/j.1460-9568.2001.01633.x

Lonergan, M. E., Gafford, G. M., Jarome, T. J., and Helmstetter, F. J. (2010). Timedependent expression of Arc and zif268 after acquisition of fear conditioning. Neural Plast. 2010:139891. doi: 10.1155/2010/139891

Lu, Y., Christian, K., and Lu, B. (2008). BDNF: a key regulator for protein synthesis-dependent LTP and long-term memory? Neurobiol. Learn. Mem. 89, 312-323. doi: 10.1016/j.nlm.2007.08.018

Luo, P., Li, X., Fei, Z., and Poon, W. (2012). Scaffold protein Homer 1: implications for neurological diseases. Neurochem. Int. 61, 731-738. doi: 10.1016/j.neuint.2012.06.014

Luoni, A., Fumagalli, F., Racagni, G., and Riva, M. A. (2014a). Repeated aripiprazole treatment regulates Bdnf, Arc and Npas4 expression under basal condition as well as after an acute swim stress in the rat brain. Pharmacol. Res. 80, 1-8. doi: 10.1016/j.phrs.2013.11.008

Luoni, A., Rocha, F. F., and Riva, M. A. (2014b). Anatomical specificity in the modulation of activity-regulated genes after acute or chronic lurasidone treatment. Prog. Neuropsychopharmacol. Biol. Psychiatry 50, 94-101. doi: 10.1016/j.pnpbp.2013.12.008.

Lyford, G. L., Yamagata, K., Kaufmann, W. E., Barnes, C. A., Sanders, L. K., Copeland, N. G., et al. (1995). Arc, a growth factor and activity-regulated gene, encodes a novel cytoskeleton-associated protein that is enriched in neuronal dendrites. Neuron 14, 433-445. doi: 10.1016/0896-6273(95)90299-6

MacGibbon, G. A., Lawlor, P. A., Bravo, R., and Dragunow, M. (1994). Clozapine and haloperidol produce a differential pattern of immediate early gene expression in rat caudate-putamen, nucleus accumbens, lateral septum and islands of Calleja. Brain Res. Mol. Brain Res. 23, 21-32. doi: 10.1016/0169-328X(94)90207-0

Maddox, S. A., Monsey, M. S., and Schafe, G. E. (2011). Early growth response gene 1 (Egr-1) is required for new and reactivated fear memories in the lateral amygdala. Learn. Mem. 18, 24-38. doi: 10.1101/lm.1980211 
Maheux, J., Ethier, I., Rouillard, C., and Levesque, D. (2005). Induction patterns of transcription factors of the nur family (nurr1, nur77, and nor-1) by typical and atypical antipsychotics in the mouse brain: implication for their mechanism of action. J. Pharmacol. Exp. Ther. 313, 460-473. doi: 10.1124/jpet.104.080184

Maheux, J., Vuillier, L., Mahfouz, M., Rouillard, C., and Levesque, D. (2012). Modulation of haloperidol-induced patterns of the transcription factor Nur77 and Nor-1 expression by serotonergic and adrenergic drugs in the mouse brain. Int. J. Neuropsychopharmacol. 15, 509-521. doi: 10.1017/S1461145711000630

Manago, F., Mereu, M., Mastwal, S., Mastrogiacomo, R., Scheggia, D., Emanuele, M., et al. (2016). Genetic disruption of Arc/Arg3.1 in mice causes alterations in dopamine and neurobehavioral phenotypes related to schizophrenia. Cell Rep. 16, 2116-2128. doi: 10.1016/j.celrep.2016.07.044

Manago, F., and Papaleo, F. (2017). Schizophrenia: what's arc got to do with it? Front. Behav. Neurosci. 11:181. doi: 10.3389/fnbeh.2017.00181

Mariga, A., Glaser, J., Mathias, L., Xu, D., Xiao, M., Worley, P., et al. (2015). Definition of a bidirectional activity-dependent pathway involving BDNF and Narp. Cell Rep. 13, 1747-1756. doi: 10.1016/j.celrep.2015.10.064

Martinez-Cengotitabengoa, M., Macdowell, K. S., Alberich, S., Diaz, F. J., Garcia-Bueno, B., Rodriguez-Jimenez, R., et al. (2016). BDNF and NGF signalling in early phases of psychosis: relationship with inflammation and response to antipsychotics after 1 year. Schizophr. Bull. 42, 142-151. doi: 10.1093/schbul/sbv078.

Matosin, N., Fernandez-Enright, F., Lum, J. S., Engel, M., Andrews, J. L., Gassen, N. C., et al. (2016). Molecular evidence of synaptic pathology in the CA1 region in schizophrenia. NPJ Schizophr. 2:16022. doi: 10.1038/npjschz.2016.22

Maxwell, M. A., and Muscat, G. E. (2006). The NR4A subgroup: immediate early response genes with pleiotropic physiological roles. Nucl. Recept. Signal 4:e002. doi: $10.1621 / \mathrm{nrs} .04002$

Maze, I., and Russo, S. J. (2010). Transcriptional mechanisms: underlying addiction-related structural plasticity. Mol. Interv. 10, 219-230. doi: $10.1124 / \mathrm{mi} .10 .4 .5$

Menard, C., Gaudreau, P., and Quirion, R. (2015). Signaling pathways relevant to cognition-enhancing drug targets. Handb. Exp. Pharmacol. 228, 59-98. doi: 10.1007/978-3-319-16522-6_3

Merchant, K. M., Dobie, D. J., Filloux, F. M., Totzke, M., Aravagiri, M., and Dorsa, D. M. (1994). Effects of chronic haloperidol and clozapine treatment on neurotensin and c-fos mRNA in rat neostriatal subregions. J. Pharmacol. Exp. Ther. 271, 460-471.

Messaoudi, E., Kanhema, T., Soule, J., Tiron, A., Dagyte, G., Da Silva, B., et al. (2007). Sustained Arc/Arg3.1 synthesis controls longterm potentiation consolidation through regulation of local actin polymerization in the dentate gyrus in vivo. J. Neurosci. 27, 10445-10455. doi: 10.1523/JNEUROSCI.2883-07.2007

Meyer, D., Bonhoeffer, T., and Scheuss, V. (2014). Balance and stability of synaptic structures during synaptic plasticity. Neuron 82, 430-443. doi: 10.1016/j.neuron.2014.02.031

Miller, J. C. (1990). Induction of c-fos mRNA expression in rat striatum by neuroleptic drugs. J. Neurochem. 54, 1453-1455. doi: 10.1111/j.1471-4159.1990.tb01983.x

Molteni, R., Calabrese, F., Mancini, M., Racagni, G., and Riva, M. A. (2008). Basal and stress-induced modulation of activity-regulated cytoskeletal associated protein (Arc) in the rat brain following duloxetine treatment. Psychopharmacology 201, 285-292. doi: 10.1007/s00213-008-1276-7

Moore, T. M., Brown, T., Cade, M., and Eells, J. B. (2008). Alterations in amphetamine-stimulated dopamine overflow due to the Nurr1-null heterozygous genotype and postweaning isolation. Synapse 62, 764-774. doi: $10.1002 /$ syn. 20550

Moser, M., Knoth, R., Bode, C., and Patterson, C. (2004). LE-PAS, a novel Arntdependent HLH-PAS protein, is expressed in limbic tissues and transactivates the CNS midline enhancer element. Brain Res. Mol. Brain Res. 128, 141-149. doi: 10.1016/j.molbrainres.2004.06.023

Nakahara, T., Kuroki, T., Hashimoto, K., Hondo, H., Tsutsumi, T., Motomura, K., et al. (2000). Effect of atypical antipsychotics on phencyclidineinduced expression of arc in rat brain. Neuroreport 11, 551-555. doi: 10.1097/00001756-200002280-00025

Nandra, K. S., and Agius, M. (2012). The differences between typical and atypical antipsychotics: the effects on neurogenesis. Psychiatr. Danub. 24(Suppl. 1), S95-S99.
Nestler, E. J. (2005). The neurobiology of cocaine addiction. Sci. Pract. Perspect. 3, 4-10. doi: 10.1151/spp05314

Nestler, E. J. (2015). FosB: a transcriptional regulator of stress and antidepressant responses. Eur. J. Pharmacol. 753, 66-72. doi: 10.1016/j.ejphar.2014.10.034

Neves-Pereira, M., Cheung, J. K., Pasdar, A., Zhang, F., Breen, G., Yates, P., et al. (2005). BDNF gene is a risk factor for schizophrenia in a Scottish population. Mol. Psychiatry 10, 208-212. doi: 10.1038/sj.mp.4001575

Nguyen, T. V., Kosofsky, B. E., Birnbaum, R., Cohen, B. M., and Hyman, S. E. (1992). Differential expression of c-fos and zif268 in rat striatum after haloperidol, clozapine, and amphetamine. Proc. Natl. Acad. Sci. U.S.A. 89, 4270-4274. doi: 10.1073/pnas.89.10.4270

Nnadi, C. U., and Malhotra, A. K. (2007). Individualizing antipsychotic drug therapy in schizophrenia: the promise of pharmacogenetics. Curr. Psychiatry Rep. 9, 313-318. doi: 10.1007/s11920-007-0038-2

Novak, G., Gallo, A., Zai, C. C., Meltzer, H. Y., Lieberman, J. A., Potkin, S. G., et al. (2010). Association of the orphan nuclear receptor NR4A1 with tardive dyskinesia. Psychiatr. Genet. 20, 39-43. doi: 10.1097/YPG.0b013e3283351221

O'brien, R. J., Xu, D., Petralia, R. S., Steward, O., Huganir, R. L., and Worley, P. (1999). Synaptic clustering of AMPA receptors by the extracellular immediate-early gene product Narp. Neuron 23, 309-323. doi: 10.1016/S0896-6273(00)80782-5

O'brien, R., Xu, D., Mi, R., Tang, X., Hopf, C., and Worley, P. (2002). Synaptically targeted narp plays an essential role in the aggregation of AMPA receptors at excitatory synapses in cultured spinal neurons. J. Neurosci. 22, 4487-4498. doi: 20026354

Oda, Y., Kanahara, N., and Iyo, M. (2015). Alterations of dopamine D2 receptors and related receptor-interacting proteins in schizophrenia: the pivotal position of dopamine supersensitivity psychosis in treatment-resistant schizophrenia. Int. J. Mol. Sci. 16, 30144-30163. doi: 10.3390/ijms161226228

Okada, R., Fujiwara, H., Mizuki, D., Araki, R., Yabe, T., and Matsumoto, K. (2015). Involvement of dopaminergic and cholinergic systems in social isolationinduced deficits in social affiliation and conditional fear memory in mice. Neuroscience 299, 134-145. doi: 10.1016/j.neuroscience.2015.04.064

Openshaw, R. L., Thomson, D. M., Penninger, J. M., Pratt, J. A., and Morris, B. J. (2017). Mice haploinsufficient for Map2k7, a gene involved in neurodevelopment and risk for schizophrenia, show impaired attention, a vigilance decrement deficit and unstable cognitive processing in an attentional task: impact of minocycline. Psychopharmacology 234, 293-305. doi: 10.1007/s00213-016-4463-y

Ortega-Martinez, S. (2015). A new perspective on the role of the CREB family of transcription factors in memory consolidation via adult hippocampal neurogenesis. Front. Mol. Neurosci. 8:46. doi: 10.3389/fnmol.2015.00046

Ozdemir, H., Ertugrul, A., Basar, K., and Saka, E. (2012). Differential effects of antipsychotics on hippocampal presynaptic protein expressions and recognition memory in a schizophrenia model in mice. Prog. Neuropsychopharmacol. Biol. Psychiatry 39, 62-68. doi: 10.1016/j.pnpbp.2012.05.009

Pang, P. T., and Lu, B. (2004). Regulation of late-phase LTP and long-term memory in normal and aging hippocampus: role of secreted proteins tPA and BDNF. Ageing Res. Rev. 3, 407-430. doi: 10.1016/j.arr.2004.07.002

Panja, D., Kenney, J. W., D’andrea, L., Zalfa, F., Vedeler, A., Wibrand, K., et al. (2014). Two-stage translational control of dentate gyrus LTP consolidation is mediated by sustained BDNF-TrkB signaling to MNK. Cell Rep. 9, 1430-1445. doi: 10.1016/j.celrep.2014.10.016

Parikh, V., Khan, M. M., and Mahadik, S. P. (2004). Olanzapine counteracts reduction of brain-derived neurotrophic factor and TrkB receptors in rat hippocampus produced by haloperidol. Neurosci. Lett. 356, 135-139. doi: 10.1016/j.neulet.2003.10.079

Park, S. W., Lee, C. H., Lee, J. G., Lee, S. J., Kim, N. R., Choi, S. M., et al. (2009). Differential effects of ziprasidone and haloperidol on immobilization stressinduced mRNA BDNF expression in the hippocampus and neocortex of rats. J. Psychiatr. Res. 43, 274-281. doi: 10.1016/j.jpsychires.2008.05.010

Park, S. W., Lee, S. K., Kim, J. M., Yoon, J. S., and Kim, Y. H. (2006). Effects of quetiapine on the brain-derived neurotrophic factor expression in the hippocampus and neocortex of rats. Neurosci. Lett. 402, 25-29. doi: 10.1016/j.neulet.2006.03.028

Peebles, C. L., Yoo, J., Thwin, M. T., Palop, J. J., Noebels, J. L., and Finkbeiner, S. (2010). Arc regulates spine morphology and maintains 
network stability in Vivo. Proc. Natl. Acad Sci. USA 107, 18173-18178. doi: 10.1073/pnas.1006546107

Pei, Q., Tordera, R., Sprakes, M., and Sharp, T. (2004). Glutamate receptor activation is involved in 5-HT2 agonist-induced Arc gene expression in the rat cortex. Neuropharmacology 46, 331-339. doi: 10.1016/j.neuropharm.2003.09.017

Penke, Z., Chagneau, C., and Laroche, S. (2011). Contribution of Egr1/zif268 to activity-dependent Arc/Arg3.1 transcription in the dentate gyrus and area CA1 of the Hippocampus. Front. Behav. Neurosci. 5:48. doi: 10.3389/fnbeh.2011.00048

Penzes, P., Cahill, M. E., Jones, K. A., Vanleeuwen, J. E., and Woolfrey, K. M. (2011). Dendritic spine pathology in neuropsychiatric disorders. Nat. Neurosci. 14, 285-293. doi: 10.1038/nn.2741

Perez-Cadahia, B., Drobic, B., and Davie, J. R. (2011). Activation and function of immediate-early genes in the nervous system. Biochem. Cell Biol. 89, 61-73. doi: 10.1139/O10-138.

Pillai, A., Terry, A. V. Jr., and Mahadik, S. P. (2006). Differential effects of long-term treatment with typical and atypical antipsychotics on NGF and BDNF levels in rat striatum and hippocampus. Schizophr. Res. 82, 95-106. doi: 10.1016/j.schres.2005.11.021

Plath, N., Ohana, O., Dammermann, B., Errington, M. L., Schmitz, D., Gross, C., et al. (2006). Arc/Arg3.1 is essential for the consolidation of synaptic plasticity and memories. Neuron 52, 437-444. doi: 10.1016/j.neuron.2006.08.024

Polese, D., De Serpis, A. A., Ambesi-Impiombato, A., Muscettola, G., and De Bartolomeis, A. (2002). Homer la gene expression modulation by antipsychotic drugs: involvement of the glutamate metabotropic system and effects of D-cycloserine. Neuropsychopharmacology 27, 906-913. doi: 10.1016/S0893-133X(02)00371-8

Purcell, S. M., Moran, J. L., Fromer, M., Ruderfer, D., Solovieff, N., Roussos, P., et al. (2014). A polygenic burden of rare disruptive mutations in schizophrenia. Nature 506, 185-190. doi: 10.1038/nature12975

Ragan, T., Kadiri, L. R., Venkataraju, K. U., Bahlmann, K., Sutin, J., Taranda, J., et al. (2012). Serial two-photon tomography for automated ex vivo mouse brain imaging. Nat. Methods 9, 255-258. doi: 10.1038/nmeth.1854

Raivich, G., and Behrens, A. (2006). Role of the AP-1 transcription factor cJun in developing, adult and injured brain. Prog. Neurobiol. 78, 347-363. doi: 10.1016/j.pneurobio.2006.03.006

Renier, N., Adams, E. L., Kirst, C., Wu, Z., Azevedo, R., Kohl, J., et al. (2016). Mapping of brain activity by automated volume analysis of immediate early genes. Cell 165, 1789-1802. doi: 10.1016/j.cell.2016.05.007

Rex, C. S., Lauterborn, J. C., Lin, C. Y., Kramar, E. A., Rogers, G. A., Gall, C. M., et al. (2006). Restoration of long-term potentiation in middleaged hippocampus after induction of brain-derived neurotrophic factor. $J$. Neurophysiol. 96, 677-685. doi: 10.1152/jn.00336.2006

Rial Verde, E. M., Lee-Osbourne, J., Worley, P. F., Malinow, R., and Cline, H. T. (2006). Increased expression of the immediate-early gene $\operatorname{arc} / \arg 3.1$ reduces AMPA receptor-mediated synaptic transmission. Neuron 52, 461-474. doi: 10.1016/j.neuron.2006.09.031

Rinaldi, A., Mandillo, S., Oliverio, A., and Mele, A. (2007). D1 and D2 receptor antagonist injections in the prefrontal cortex selectively impair spatial learning in mice. Neuropsychopharmacology 32, 309-319. doi: 10.1038/sj.npp.1301176

Rizig, M. A., McQuillin, A., Ng, A., Robinson, M., Harrison, A., Zvelebil, M., et al. (2012). A gene expression and systems pathway analysis of the effects of clozapine compared to haloperidol in the mouse brain implicates susceptibility genes for schizophrenia. J. Psychopharmacol. 26, 1218-1230. doi: $10.1177 / 0269881112450780$

Robbins, M. J., Critchlow, H. M., Lloyd, A., Cilia, J., Clarke, J. D., Bond, B., et al. (2008). Differential expression of IEG mRNA in rat brain following acute treatment with clozapine or haloperidol: a semi-quantitative RT-PCR study. J. Psychopharmacol. 22, 536-542. doi: 10.1177/0269881107081521

Robertson, G. S., and Fibiger, H. C. (1996). Effects of olanzapine on regional C-Fos expression in rat forebrain. Neuropsychopharmacology 14, 105-110. doi: 10.1016/0893-133X(95)00196-K

Robertson, G. S., Matsumura, H., and Fibiger, H. C. (1994). Induction patterns of Fos-like immunoreactivity in the forebrain as predictors of atypical antipsychotic activity. J. Pharmacol. Exp. Ther. 271, 1058-1066.

Robinet, C., and Pellerin, L. (2011). Brain-derived neurotrophic factor enhances the hippocampal expression of key postsynaptic proteins in vivo including the monocarboxylate transporter MCT2. Neuroscience 192, 155-163. doi: 10.1016/j.neuroscience.2011.06.059

Robinet, E. A., Geurts, M., Maloteaux, J. M., and Pauwels, P. J. (2001). Chronic treatment with certain antipsychotic drugs preserves upregulation of regulator of G-protein signalling 2 mRNA in rat striatum as opposed to c-fos mRNA. Neurosci. Lett. 307, 45-48. doi: 10.1016/S0304-3940(01)01923-1

Rodriguez, J. J., Garcia, D. R., Nakabeppu, Y., and Pickel, V. M. (2001). FosB in rat striatum: normal regional distribution and enhanced expression after 6-month haloperidol administration. Synapse 39, 122-132. doi: 10.1002/1098-2396(200102)39:2\&lt;122::AID-SYN3\&gt;3.0.CO;2-R

Rojas, P., Joodmardi, E., Hong, Y., Perlmann, T., and Ogren, S. O. (2007). Adult mice with reduced Nurr1 expression: an animal model for schizophrenia. Mol. Psychiatry 12, 756-766. doi: 10.1038/sj.mp.4001993

Sakuma, K., Komatsu, H., Maruyama, M., Imaichi, S., Habata, Y., and Mori, M. (2015). Temporal and spatial transcriptional fingerprints by antipsychotic or propsychotic drugs in mouse brain. PLOS ONE 10:e0118510. doi: 10.1371/journal.pone.0118510

Samaha, A. N., Reckless, G. E., Seeman, P., Diwan, M., Nobrega, J. N., and Kapur, S. (2008). Less is more: antipsychotic drug effects are greater with transient rather than continuous delivery. Biol. Psychiatry 64, 145-152. doi: 10.1016/j.biopsych.2008.01.010

Saunderson, E. A., Spiers, H., Mifsud, K. R., Gutierrez-Mecinas, M., Trollope, A. F., Shaikh, A., et al. (2016). Stress-induced gene expression and behavior are controlled by DNA methylation and methyl donor availability in the dentate gyrus. Proc. Natl. Acad. Sci. U.S.A. 113, 4830-4835. doi: $10.1073 /$ pnas. 1524857113

Sauvage, M. M., Nakamura, N. H., and Beer, Z. (2013). Mapping memory function in the medial temporal lobe with the immediate-early gene Arc. Behav. Brain Res. 254, 22-33. doi: 10.1016/j.bbr.2013.04.048

Schubert, K. O., Focking, M., Wynne, K., and Cotter, D. R. (2016). Proteome and pathway effects of chronic haloperidol treatment in mouse hippocampus. Proteomics 16, 532-538. doi: 10.1002/pmic.201500242

Seeman, M. V., and Seeman, P. (2014). Is schizophrenia a dopamine supersensitivity psychotic reaction? Prog. Neuropsychopharmacol. Biol. Psychiatry 48, 155-160. doi: 10.1016/j.pnpbp.2013.10.003

Seeman, P. (2002). Atypical antipsychotics: mechanism of action. Can. J. Psychiatry 47, 27-38. doi: 10.1177/070674370204700106

Semba, J., Sakai, M. W., Suhara, T., and Akanuma, N. (1999). Differential effects of acute and chronic treatment with typical and atypical neuroleptics on c-fos mRNA expression in rat forebrain regions using non-radioactive in situ hybridization. Neurochem. Int. 34, 269-277. doi: 10.1016/S0197-0186(99)00009-1

Serchov, T., Heumann, R., Van Calker, D., and Biber, K. (2016). Signaling pathways regulating Homer1a expression: implications for antidepressant therapy. Biol. Chem. 397, 207-214. doi: 10.1515/hsz-2015-0267

Shamloo, M., Soriano, L., Von Schack, D., Rickhag, M., Chin, D. J., GonzalezZulueta, M., et al. (2006). Npas4, a novel helix-loop-helix PAS domain protein, is regulated in response to cerebral ischemia. Eur. J. Neurosci. 24, 2705-2720. doi: 10.1111/j.1460-9568.2006.05172.x

Shen, X., Purser, C., Tien, L. T., Chiu, C. T., Paul, I. A., Baker, R., et al. (2010). muOpioid receptor knockout mice are insensitive to methamphetamine-induced behavioral sensitization. J. Neurosci. Res. 88, 2294-2302. doi: 10.1002/jnr.22386

Shepard, R., Heslin, K., and Coutellier, L. (2017). The transcription factor Npas4 contributes to adolescent development of prefrontal inhibitory circuits, and to cognitive and emotional functions: implications for neuropsychiatric disorders. Neurobiol. Dis. 99, 36-46. doi: 10.1016/j.nbd.2016.12.012

Shin, S. M., Zhang, N., Hansen, J., Gerges, N. Z., Pak, D. T., Sheng, M., et al. (2012). GKAP orchestrates activity-dependent postsynaptic protein remodeling and homeostatic scaling. Nat. Neurosci. 15, 1655-1666. doi: 10.1038/nn.3259

Shiraishi-Yamaguchi, Y., and Furuichi, T. (2007). The homer family proteins. Genome Biol. 8:206. doi: 10.1186/gb-2007-8-2-206

Shirayama, Y., Hashimoto, K., Matsuki, H., Tsunashima, K., Iyo, M., Higuchi, T., et al. (1999). Increased expression of zif268 mRNA in rat retrosplenial cortex following administration of phencyclidine. Brain Res. 839, 180-185. doi: 10.1016/S0006-8993(99)01738-2

Snyder, J. S., Clifford, M. A., Jeurling, S. I., and Cameron, H. A. (2012). Complementary activation of hippocampal-cortical subregions and immature neurons following chronic training in single and multiple context versions 
of the water maze. Behav. Brain Res. 227, 330-339. doi: 10.1016/j.bbr.2011. 06.025

Spellmann, I., Rujescu, D., Musil, R., Mayr, A., Giegling, I., Genius, J., et al. (2011). Homer-1 polymorphisms are associated with psychopathology and response to treatment in schizophrenic patients. J. Psychiatr. Res. 45, 234-241. doi: 10.1016/j.jpsychires.2010.06.004

Srivas, S., and Thakur, M. K. (2016). Epigenetic regulation of neuronal immediate early genes is associated with decline in their expression and memory consolidation in scopolamine-induced amnesic mice. Mol. Neurobiol. 54, 5107-5119. doi: 10.1007/s12035-016-0047-4

Steward, O., Farris, S., Pirbhoy, P. S., Darnell, J., and Driesche, S. J. (2014). Localization and local translation of Arc/Arg3.1 mRNA at synapses: some observations and paradoxes. Front. Mol. Neurosci. 7:101. doi: $10.3389 /$ fnmol.2014.00101.

Steward, O., and Worley, P. F. (2001). A cellular mechanism for targeting newly synthesized mRNAs to synaptic sites on dendrites. Proc. Natl. Acad. Sci. U.S.A. 98, 7062-7068. doi: 10.1073/pnas.131146398

Szumlinski, K. K., Abernathy, K. E., Oleson, E. B., Klugmann, M., Lominac, K. D., He, D. Y., et al. (2006). Homer isoforms differentially regulate cocaine-induced neuroplasticity. Neuropsychopharmacology 31, 768-777. doi: 10.1038/sj.npp.1300890

Szumlinski, K. K., Dehoff, M. H., Kang, S. H., Frys, K. A., Lominac, K. D., Klugmann, M., et al. (2004). Homer proteins regulate sensitivity to cocaine. Neuron 43, 401-413. doi: 10.1016/j.neuron.2004.07.019

Szumlinski, K. K., Lominac, K. D., Kleschen, M. J., Oleson, E. B., Dehoff, M. H., Schwarz, M. K., et al. (2005). Behavioral and neurochemical phenotyping of Homerl mutant mice: possible relevance to schizophrenia. Genes Brain Behav. 4, 273-288. doi: 10.1111/j.1601-183X.2005.00120.x

Takahashi, T., Suzuki, M., Tsunoda, M., Kawamura, Y., Takahashi, N., Tsuneki, H., et al. (2008). Association between the brain-derived neurotrophic factor Val66Met polymorphism and brain morphology in a Japanese sample of schizophrenia and healthy comparisons. Neurosci. Lett. 435, 34-39. doi: 10.1016/j.neulet.2008.02.004

Tan, Y. L., Zhou, D. F., Cao, L. Y., Zou, Y. Z., and Zhang, X. Y. (2005). Decreased BDNF in serum of patients with chronic schizophrenia on long-term treatment with antipsychotics. Neurosci. Lett. 382, 27-32. doi: 10.1016/j.neulet.2005.02.054

Tetradis, S., Bezouglaia, O., Tsingotjidou, A., and Vila, A. (2001). Regulation of the nuclear orphan receptor Nur77 in bone by parathyroid hormone. Biochem. Biophys. Res. Commun. 281, 913-916. doi: 10.1006/bbrc.2001.4459

Tien, L. T., Ho, I. K., and Ma, T. (2010). Methamphetamine-induced expression of zif268 mRNA is prevented by haloperidol in mice lacking mu-opioid receptor. Neurotoxicology 31, 326-330. doi: 10.1016/j.neuro.2010.02.002

Tomasetti, C., Dell'aversano, C., Iasevoli, F., and De Bartolomeis, A. (2007). Homer splice variants modulation within cortico-subcortical regions by dopamine D2 antagonists, a partial agonist, and an indirect agonist: implication for glutamatergic postsynaptic density in antipsychotics action. Neuroscience 150, 144-158. doi: 10.1016/j.neuroscience.2007.08.022

Tomasetti, C., Dell'aversano, C., Iasevoli, F., Marmo, F., and De Bartolomeis, A. (2011). The acute and chronic effects of combined antipsychotic-mood stabilizing treatment on the expression of cortical and striatal postsynaptic density genes. Prog. Neuropsychopharmacol. Biol. Psychiatry 35, 184-197. doi: 10.1016/j.pnpbp.2010.10.025

Tost, H., Braus, D. F., Hakimi, S., Ruf, M., Vollmert, C., Hohn, F., et al. (2010). Acute D2 receptor blockade induces rapid, reversible remodeling in human cortical-striatal circuits. Nat. Neurosci. 13, 920-922. doi: 10.1038/nn.2572

Tsui, C. C., Copeland, N. G., Gilbert, D. J., Jenkins, N. A., Barnes, C., and Worley, P. F. (1996). Narp, a novel member of the pentraxin family, promotes neurite outgrowth and is dynamically regulated by neuronal activity. J. Neurosci. 16, 2463-2478.

Vahid-Ansari, F., Nakabeppu, Y., and Robertson, G. S. (1996). Contrasting effects of chronic clozapine, Seroquel(TM) (ICI 204,636) and haloperidol administration of deltaFosB-like immunoreactivity in the rodent forebrain. Eur. J. Neurosci. 8, 927-936. doi: 10.1111/j.1460-9568.1996.tb01579.x

Valenti, O., and Grace, A. A. (2010). Antipsychotic drug-induced increases in ventral tegmental area dopamine neuron population activity via activation of the nucleus accumbens-ventral pallidum pathway. Int. J. Neuropsychopharmacol. 13, 845-860. doi: 10.1017/S1461145709990599
Vazdarjanova, A., McNaughton, B. L., Barnes, C. A., Worley, P. F., and Guzowski, J. F. (2002). Experience-dependent coincident expression of the effector immediate-early genes arc and Homer 1a in hippocampal and neocortical neuronal networks. J. Neurosci. 22, 10067-10071.

Verma, V., Lim, E. P., Han, S. P., Nagarajah, R., and Dawe, G. S. (2007). Chronic high-dose haloperidol has qualitatively similar effects to risperidone and clozapine on immediate-early gene and tyrosine hydroxylase expression in the rat locus coeruleus but not medial prefrontal cortex. Neurosci. Res. 57, 17-28. doi: 10.1016/j.neures.2006.09.002

Verma, V., Rasmussen, K., and Dawe, G. S. (2006). Effects of short-term and chronic olanzapine treatment on immediate early gene protein and tyrosine hydroxylase immunoreactivity in the rat locus coeruleus and medial prefrontal cortex. Neuroscience 143, 573-585. doi: 10.1016/j.neuroscience.2006. 08.010

Vita, A., De Peri, L., Deste, G., Barlati, S., and Sacchetti, E. (2015). The Effect of antipsychotic treatment on cortical gray matter changes in schizophrenia: does the class matter? A meta-analysis and meta-regression of longitudinal magnetic resonance imaging studies. Biol. Psychiatry 78, 403-412. doi: 10.1016/j.biopsych.2015.02.008

Wallace, C. S., Lyford, G. L., Worley, P. F., and Steward, O. (1998). Differential intracellular sorting of immediate early gene mRNAs depends on signals in the mRNA sequence. J. Neurosci. 18, 26-35.

Waller, J. A., Tamm, J. A., Abdourahman, A., Pehrson, A. L., Li, Y., Cajina, M., et al. (2017). Chronic vortioxetine treatment in rodents modulates gene expression of neurodevelopmental and plasticity markers. Eur. Neuropsychopharmacol. 27, 192-203. doi: 10.1016/j.euroneuro.2016.11.014

Wang, H. X., and Gao, W. J. (2012). Prolonged exposure to NMDAR antagonist induces cell-type specific changes of glutamatergic receptors in rat prefrontal cortex. Neuropharmacology 62, 1808-1822. doi: 10.1016/j.neuropharm.2011.11.024

Waterhouse, E. G., and Xu, B. (2009). New insights into the role of brain-derived neurotrophic factor in synaptic plasticity. Mol. Cell. Neurosci. 42, 81-89. doi: 10.1016/j.mcn.2009.06.009

Weickert, C. S., Hyde, T. M., Lipska, B. K., Herman, M. M., Weinberger, D. R., and Kleinman, J. E. (2003). Reduced brain-derived neurotrophic factor in prefrontal cortex of patients with schizophrenia. Mol. Psychiatry 8, 592-610. doi: 10.1038/sj.mp.4001308

Weinberger, D. R., and Berman, K. F. (1996). Prefrontal function in schizophrenia: confounds and controversies. Philos. Trans. R. Soc. Lond. B Biol. Sci. 351, 1495-1503. doi: 10.1098/rstb.1996.0135

Werme, M., Ringholm, A., Olson, L., and Brene, S. (2000). Differential patterns of induction of NGFI-B, Norl and c-fos mRNAs in striatal subregions by haloperidol and clozapine. Brain Res. 863, 112-119. doi: 10.1016/S0006-8993(00)02109-0

Wheeler, A. L., Creed, M. C., Voineskos, A. N., and Nobrega, J. N. (2014). Changes in brain functional connectivity after chronic haloperidol in rats: a network analysis. Int. J. Neuropsychopharmacol. 17, 1129-1138. doi: 10.1017/S1461145714000042

White, N. M., and Hiroi, N. (1998). Preferential localization of self-stimulation sites in striosomes/patches in the rat striatum. Proc. Natl. Acad. Sci. U.S.A. 95, 6486-6491. doi: 10.1073/pnas.95.11.6486

Wibrand, K., Pai, B., Siripornmongcolchai, T., Bittins, M., Berentsen, B., Ofte, M. L., et al. (2012). MicroRNA regulation of the synaptic plasticity-related gene Arc. PLoS ONE 7:e41688. doi: 10.1371/journal.pone.0041688

Wiig, K. A., Whitlock, J. R., Epstein, M. H., Carpenter, R. L., and Bear, M. F. (2009). The levo enantiomer of amphetamine increases memory consolidation and gene expression in the hippocampus without producing locomotor stimulation. Neurobiol. Learn. Mem. 92, 106-113. doi: 10.1016/j.nlm.2009.02.001

Xie, H., Liu, Y., Zhu, Y., Ding, X., Yang, Y., and Guan, J. S. (2014). In vivo imaging of immediate early gene expression reveals layer-specific memory traces in the mammalian brain. Proc. Natl. Acad. Sci. U.S.A. 111, 2788-2793. doi: 10.1073/pnas.1316808111

Xing, G., Zhang, L., Russell, S., and Post, R. (2006). Reduction of dopaminerelated transcription factors Nurrl and NGFI-B in the prefrontal cortex in schizophrenia and bipolar disorders. Schizophr. Res. 84, 36-56. doi: 10.1016/j.schres.2005.11.006

Xu, B., Gottschalk, W., Chow, A., Wilson, R. I., Schnell, E., Zang, K., et al. (2000). The role of brain-derived neurotrophic factor receptors in the mature 
hippocampus: modulation of long-term potentiation through a presynaptic mechanism involving TrkB. J. Neurosci. 20, 6888-6897.

Yamada, H., Kuroki, T., Nakahara, T., Hashimoto, K., Tsutsumi, T., Hirano, M., et al. (2007). The dopamine D1 receptor agonist, but not the D2 receptor agonist, induces gene expression of Homer 1a in rat striatum and nucleus accumbens. Brain Res. 1131, 88-96. doi: 10.1016/j.brainres.2006.11.011

Yano, H., Ninan, I., Zhang, H., Milner, T. A., Arancio, O., and Chao, M. V. (2006). BDNF-mediated neurotransmission relies upon a myosin VI motor complex. Nat. Neurosci. 9, 1009-1018. doi: 10.1038/nn1730

Yano, M., and Steiner, H. (2005). Methylphenidate (Ritalin) induces Homer 1a and zif 268 expression in specific corticostriatal circuits. Neuroscience 132, 855-865. doi: 10.1016/j.neuroscience.2004.12.019

Yin, D. M., Chen, Y. J., Sathyamurthy, A., Xiong, W. C., and Mei, L. (2012). Synaptic dysfunction in schizophrenia. Adv. Exp. Med. Biol. 970, 493-516. doi: 10.1007/978-3-7091-0932-8_22

Young, C. D., Meltzer, H. Y., and Deutch, A. Y. (1998). Effects of desmethylclozapine on Fos protein expression in the forebrain: in vivo biological activity of the clozapine metabolite. Neuropsychopharmacology 19, 99-103. doi: 10.1016/S0893-133X(97)00203-0

Yue, Y., Kong, L., Wang, J., Li, C., Tan, L., Su, H., et al. (2016). Regional abnormality of grey matter in schizophrenia: effect from the illness or treatment? PLoS ONE 11:e0147204. doi: 10.1371/journal.pone.0147204

Zai, C. C., Tiwari, A. K., De Luca, V., Muller, D. J., Bulgin, N., Hwang, R., et al. (2009). Genetic study of BDNF, DRD3, and their interaction in tardive dyskinesia. Eur. Neuropsychopharmacol. 19, 317-328. doi: 10.1016/j.euroneuro.2009.01.001
Zhang, G. C., Mao, L. M., Liu, X. Y., Parelkar, N. K., Arora, A., Yang, L., et al. (2007). In vivo regulation of Homerla expression in the striatum by cocaine. Mol. Pharmacol. 71, 1148-1158. doi: 10.1124/mol.106.028399

Zhang, W., Wu, J., Ward, M. D., Yang, S., Chuang, Y. A., Xiao, M., et al. (2015). Structural basis of arc binding to synaptic proteins: implications for cognitive disease. Neuron 86, 490-500. doi: 10.1016/j.neuron.2015.03.030

Zhang, X. Y., Chen, D. C., Tan, Y. L., Tan, S. P., Luo, X., Zuo, L., et al. (2016). BDNF polymorphisms are associated with schizophrenia onset and positive symptoms. Schizophr. Res. 170, 41-47. doi: 10.1016/j.schres.2015.11.009

Zhou, X., Moon, C., Zheng, F., Luo, Y., Soellner, D., Nunez, J. L., et al. (2009). N-methyl-D-aspartate-stimulated ERK1/2 signaling and the transcriptional up-regulation of plasticity-related genes are developmentally regulated following in vitro neuronal maturation. J. Neurosci. Res. 87, 2632-2644. doi: $10.1002 /$ jnr.22103

Conflict of Interest Statement: The authors declare that the research was conducted in the absence of any commercial or financial relationships that could be construed as a potential conflict of interest.

Copyright (C) 2017 de Bartolomeis, Buonaguro, Latte, Rossi, Marmo, Iasevoli and Tomasetti. This is an open-access article distributed under the terms of the Creative Commons Attribution License (CC BY). The use, distribution or reproduction in other forums is permitted, provided the original author(s) or licensor are credited and that the original publication in this journal is cited, in accordance with accepted academic practice. No use, distribution or reproduction is permitted which does not comply with these terms. 